\title{
Numerical Analysis of Temperature Reduction Effect of Permeable Pavements
}

\section{Zhe Liu ( $\nabla 16085333 @ q q . c o m$ )}

Changan University: Chang'an University https://orcid.org/0000-0001-8978-7521

\section{Yuxiang Tian}

Chang'an University

\section{Biao Ma}

Changan University: Chang'an University

\section{Wei Si}

Changan University: Chang'an University

\section{Xiaoqing Wang}

Changan University: Chang'an University

\section{Research Article}

Keywords: permeable pavement, finite element analysis, influencing factors, water holding status, road surface temperature, cooling effect

Posted Date: June 1st, 2021

DOI: https://doi.org/10.21203/rs.3.rs-287873/v1

License: (c) (i) This work is licensed under a Creative Commons Attribution 4.0 International License.

Read Full License 
Numerical analysis of temperature reduction effect of permeable pavements

Xi'an, Shaanxi 710064, China

Biao Ma, Ph.D

Chang'an University, Xi'an, China

Phone: +86 (029) 61105193

E-mail: mabiaochd@163.com

Abstract: Permeable pavements can effectively reduce the urban road surface temperatures. To study the cooling effect of holding water on the road surface under the comprehensive influence of the external water and heat environment, a numerical model established by a finite element analysis software and an indoor test were used to verify the temperature change behavior of the road surface under different heating temperatures and holding water conditions. The results show that the average error between the numerical model and indoor test is $3.5 \%$, and the model reliability is high. Under the same conditions, the change in thickness of the permeable pavement surface and base course has a negligible effect on the temperature of the road surface. For every $100 \mathrm{~J} /\left(\mathrm{kg} /{ }^{\circ} \mathrm{C}\right)$ increase in the specific heat capacity of the upper surface course and lower surface course, the maximum daily road surface temperature can be reduced by approximately $2.1{ }^{\circ} \mathrm{C}$ and $0.4{ }^{\circ} \mathrm{C}$, respectively. The road surface temperature shows a similar pattern when the thermal conductivity increases. Under dry conditions, the maximum daily road surface temperature can be reduced by approximately $3.4{ }^{\circ} \mathrm{C}$ and $4.3{ }^{\circ} \mathrm{C}$ for surface-permeable and fully permeable pavements, respectively. This study provides reference suggestions for optimizing the selection and design of urban 
road pavement structures from the perspectives of permeable pavement design, material parameters, and structure

type.

24 keyword: permeable pavement; finite element analysis; influencing factors; water holding status; road surface temperature; cooling effect

26

\section{Introduction}

With the rapid expansion of the urban scale and urban population, the phenomena of "urban rain island" and "heat island effect" have become increasingly serious (Sun et al. 2019; Zhou et al. 2012). The urban road permeable pavement is an important part of the "sponge city." Compared with the traditional paved road, it has a large porosity and strong permeability, so that the rainwater within the city rapidly infiltrates the road surface, thus reducing the pressure of urban waterlogging (Niu et al. 2016; Roseen et al. 2009). It can store water while using water evaporation to take away heat from the road surface, therefore reducing the temperature of the road pavement and effectively alleviating the "heat island effect" of the city (Booth and Leavitt 1999; Haselbach et al. 2011; Ikechukwu 2015; Li et al. 2019). To date, scholars have conducted numerous studies on the drainage and cooling effects of permeable pavements. In terms of drainage action, Kuang et al. (Kuang et al. 2010) developed a permeability performance prediction model for permeable asphalt pavements to provide a reference for the analysis of the permeability capacity of permeable pavements. Li et al. (Hou et al. 2020; Palla et al. 2015) demonstrated the role of permeable pavements in relieving urban drainage pressure through indoor simulation tests. Wang (Hongshan 2017) established a rainwater infiltration model for permeable pavements and studied the influence of rainfall intensity on the rainwater infiltration of permeable pavements. Jiang et al. (Wei et al. 2013) established a water storage-infiltration model for permeable asphalt pavements based on meteorological and hydraulic theories to calculate and analyze their drainage effectiveness. Various studies have shown that permeable pavements can effectively infiltrate rainwater and reduce 
surface runoff compared to conventional pavements, and the establishment of relevant infiltration models has

has a significant impact on surface temperature and suggested that permeable pavements can be used to mitigate urban thermal effects. Wang et al. (Liu et al. 2018; Wang et al. 2018) studied the effect of evaporative cooling of permeable paving materials on the outdoor thermal environment. Li et al. (Li et al. 2013a; Li et al. 2016) found that permeable pavements were effective in reducing the surface temperature in the wet state, but the opposite was true in the dry, water-free state. Nemirovsky et al. (Li et al. 2014; Li et al. 2013b; Nemirovsky et al. 2013) found that moisture near the surface in the permeable pavement construction layer has a large effect on cooling, and moisture at deeper levels can be neglected. Nakayama et al. (Nakayama and Fujita 2010) used NICE-UBBREN to simulate the cooling effect of urban permeable pavements in summer and showed that there is a strong relationship between temperature decrease, surface evaporation, and pavement water capacity. Jiang (Fu 2011) used ANSYS to study the cooling effect of a permeable pavement under the combined effect of heat conduction and heat convection, and the results showed a positive linear relationship between its cooling effect and void fraction. Scholars mainly study the cooling effect through outdoor measurements and mathematical models, and the analysis of the factors affecting the cooling effect and its optimization is one of the active areas of research.

In summary, there have been numerous analyses on the various properties of permeable pavements, which have

59 laid the foundation for the research on drainage and temperature reduction of permeable pavement structures.

60 However, the existing studies have not addressed the influence of the permeable pavement structure thermal physical

61 parameters, pavement type, and water-holding state on road surface cooling. This study establishes the temperature

62 change calculation model of permeable pavement structures with the help of finite element analysis software, calculates the temperature change of a permeable pavement structure under different conditions numerically, 
values of the numerical calculation model. It establishes a numerical calculation model of the road surface

variable method. It also compares the changes in road surface temperature of different types of pavement structures, pavement type, water holding state, and road surface cooling effect.

\section{3}

\section{Permeable pavement model}

\subsection{Finite element modeling}

1) Introduction to finite element models

Because of the size limitation of the indoor test model, the actual road permeable pavement model could not be established. Thus, the finite element software was used to construct the numerical calculation model, and the reliability of the numerical model parameters was verified using the indoor test results. The numerical model set the side radiation coefficient to 0 , the surface film condition was used to simulate the bottom surface and environmental boundary conditions, and the film coefficient was set to 200. To ensure the accuracy of the results, a model mesh size of $1 \mathrm{~cm} \times 1 \mathrm{~cm}$ was determined by comparison, and a four-node linear heat transfer (DC2D4) cell type was used for the heat transfer analysis. The permeable pavement structure model, from top to bottom, is as follows: surface structure of $15 \mathrm{~cm}$, base course of $20 \mathrm{~cm}$, and subgrade of $20 \mathrm{~cm}$. The model width is $20 \mathrm{~cm}$. The numerical model adopts upper thermal boundary conditions, and the indoor test is heated by an upper heating control device to maintain 

model is shown in Figure 1.
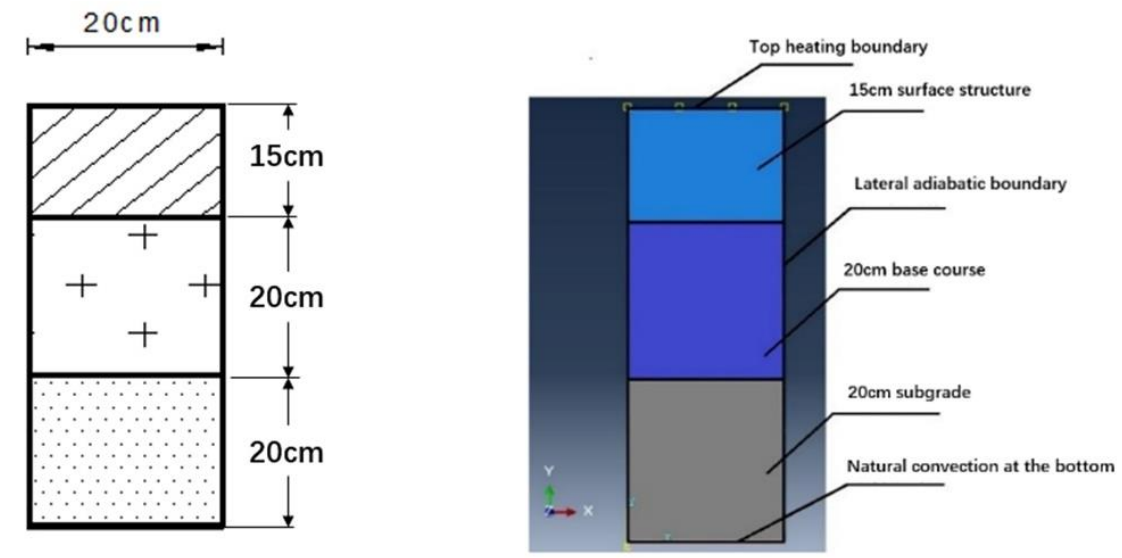

(a) Indoor test plane 2-D model (b) Numerical calculation 2-D model

Figure 1 Schematic of indoor test and numerical calculation model

2) Model underlying assumptions

According to the basic characteristics of a permeable pavement, combined with the theoretical analysis and calculation requirements, the basic assumptions of the numerical calculation model were as follows:

(1) Homogeneous and continuous medium for each layer of the permeable pavement structure;

(2) The permeable pavement structure is isotropic, and its anisotropic characteristics are not considered;

(3) The temperature and heat flow transfer of each structural layer of the permeable pavement is continuous, there is no thermal resistance in the contact between the layers, and the heat transfer interface effect between the layers is not considered.

(4) The temperature at the bottom of the subgrade is constant, and the effect of geothermal action on the temperature of the subgrade pavement is not considered.

(5) The model is fully insulated at each side boundary, and the heat dissipation effect of the model and heat exchange process with the outside world are not considered in the test. 
(6) The permeable pavement surface is set to a state of no air flow, which is consistent with the wind-free conditions of the indoor test.

The thermal conductivity of a permeable pavement material is less affected by external factors such as water

and air, and its comprehensive specific heat capacity should consider the action of air and water in addition to the

influence of asphalt and aggregate. The thermal conductivity of the pavement structure can be calculated according

to Williamson's formula ${ }^{24}$. Pavement structure in the warming process, the volume and pressure are not changed,

can be regarded as equal volume and pressure specific heat capacity, dry and water-holding state of permeable

asphalt mixture and other pavement materials integrated specific heat capacity can be calculated according to for

$C_{D}=\frac{M_{a}}{M} \times C_{a}+\frac{M_{s}}{M} \times C_{s}+\frac{M_{a i r}}{M} \times C_{a i r}$

$C_{M}=\frac{M_{a}}{M} \times C_{a}+\frac{M_{s}}{M} \times C_{s}+\frac{M_{a i r}}{M} \times C_{a i r}+\frac{M_{w}}{M} \times C_{w}$

where $C_{D}\left(\mathrm{~J} /\left(\mathrm{kg} /{ }^{\circ} \mathrm{C}\right)\right.$ is the integrated specific heat capacity of the structure in the dry state, $C_{M}\left(\mathrm{~J} /\left(\mathrm{kg} /{ }^{\circ} \mathrm{C}\right)\right)$ is the integrated specific heat capacity of the structure in the water-holding state, $M(\mathrm{~kg})$ is the structural mass, and the subscripts $a, s$, air, and $w$ are asphalt, aggregate, air, and water.

established through the available experimental data:

$S_{R}=0.629+0.047 \times V_{\text {Void }}$

119 where $S_{R}(\%)$ is the water retention rate of the specimen and $V_{\text {Void }}(\%)$ is the porosity of the specimen. 
structural layer density, and specific heat capacity were obtained from the established research results and Eqs. 1, 2, and 3 .

Table 1 Numerical model structure and parameters

\begin{tabular}{|c|c|c|c|c|c|c|}
\hline Structural layer position & $\begin{array}{l}\text { Thickness } \\
\text { (cm) }\end{array}$ & $\begin{array}{l}\text { Drying } \\
\text { density } \\
\left(\mathrm{kg} / \mathrm{m}^{3}\right)\end{array}$ & $\begin{array}{l}\text { Water } \\
\text { holding } \\
\text { density } \\
\left(\mathrm{kg} / \mathrm{m}^{3}\right)\end{array}$ & $\begin{array}{c}\text { Dry specific } \\
\text { heat capacity } \\
\left(\mathbf{J} /\left(\mathbf{k g} /{ }^{\circ} \mathbf{C}\right)\right.\end{array}$ & $\begin{array}{c}\text { Specific heat } \\
\text { capacity } \\
\text { holding water } \\
\left(\mathrm{J} /\left(\mathrm{kg} /{ }^{\circ} \mathrm{C}\right)\right.\end{array}$ & $\begin{array}{c}\text { Thermal } \\
\text { conductivity } \\
\left(\mathbf{W} / \mathbf{m} \cdot{ }^{\circ} \mathbf{C}\right)\end{array}$ \\
\hline $\begin{array}{c}\text { Permeable asphalt mixture } \\
\text { surface course }\end{array}$ & 15 & 2250 & 2287 & 865 & 990 & $0.7-1.1$ \\
\hline $\begin{array}{c}\text { graded crushed stone base } \\
\text { course }\end{array}$ & 20 & 2430 & 2495 & 850 & 1010 & $0.8-1.2$ \\
\hline subgrade & 20 & 1975 & 1997 & 850 & 995 & $0.8-1.5$ \\
\hline
\end{tabular}

\subsection{Model reliability verification}

The indoor test model for permeable pavement temperature change used a $20 \mathrm{~cm}$ in diameter, $80 \mathrm{~cm}$ in height, and $2 \mathrm{~cm}$ in thickness cylindrical glass test barrel. Model side with height scale, along the vertical direction every $5 \mathrm{~cm}$ set $1 \mathrm{~cm}$ diameter small hole, for the drainage pipe and temperature sensor to leave the hole channel. Bury the temperature sensor as required. For the test, at the three interfaces, a PT100 RTD temperature sensor was used with display accuracy of $0.1{ }^{\circ} \mathrm{C}$, and a $500 \mathrm{~W}$ round plate type cast aluminum electric heating plate was adopted for the upper surface temperature control heating. The indoor test model is shown in Figure 2.
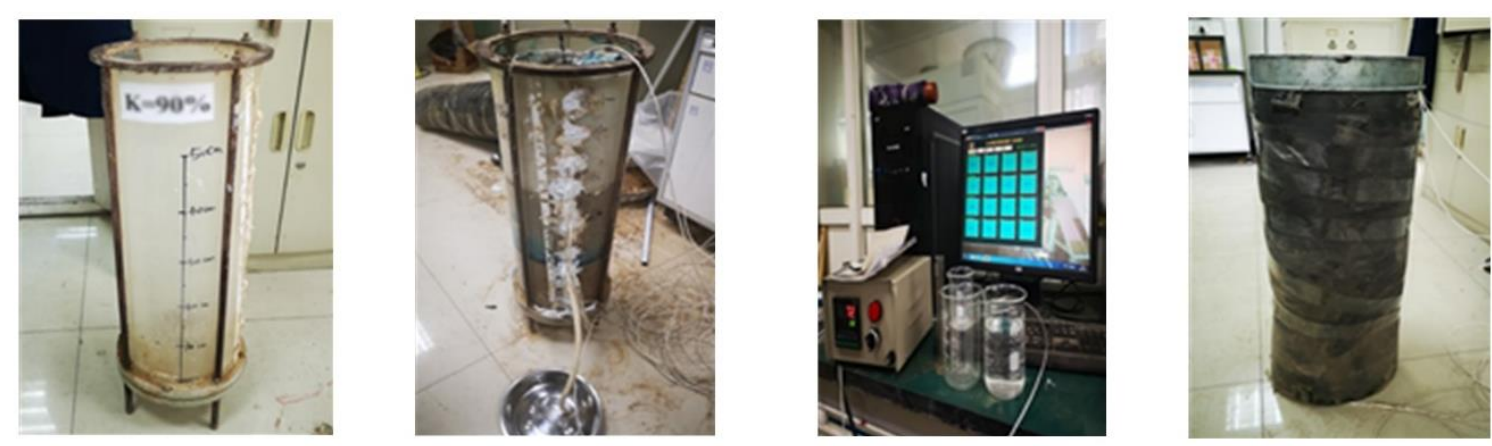

(a) Permeable paving test bucket (b) Temperature sensor and drain pipe (c) Intelligent temperature control equipment (d) Model insulation wrap

Figure 2 Indoor test model of permeable pavement 
with surface temperature loads of $40{ }^{\circ} \mathrm{C}, 50{ }^{\circ} \mathrm{C}$, and $60{ }^{\circ} \mathrm{C}$ applied to the upper surface and a loading time of $12 \mathrm{~h}$.

where $T_{C}\left({ }^{\circ} \mathrm{C}\right)$ is the calculated value of the numerical model temperature, $T_{M}\left({ }^{\circ} \mathrm{C}\right)$ is the measured indoor test

temperature, $e(\%)$ is the computational error, and $A b s$ is an absolute value function.

$40-60^{\circ} \mathrm{C}$ are shown in Figure 3.

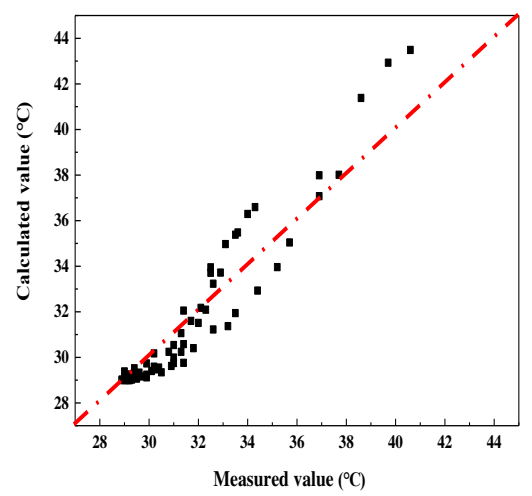

(a) $45^{\circ}$ contour plot at $40^{\circ} \mathrm{C}$

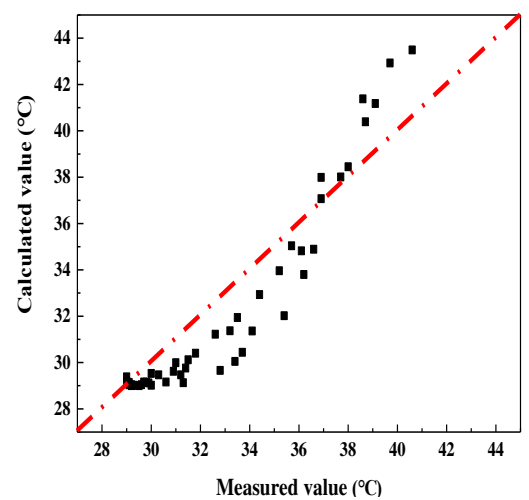

(b) $45^{\circ}$ contour plot at $50^{\circ} \mathrm{C}$

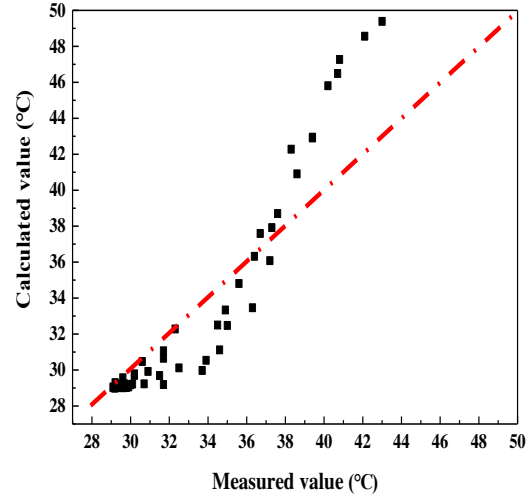

(c) $45^{\circ}$ contour plot at $60^{\circ} \mathrm{C}$

Figure $345^{\circ}$ contour plot of measured and calculated values at $40-60^{\circ} \mathrm{C}$

From the results of the $45^{\circ}$ contour map in Figure 3, it can be observed that the obtained points in the coordinate

system are basically near the $45^{\circ}$ contour, there are no obvious data anomalies, and the resultant errors are well correlated with the depth of the model location. The average calculation errors of the 5,10 , and $15 \mathrm{~cm}$ surface depth 
153 locations for each loading condition were calculated to be $7.18 \%, 4.69 \%$, and $4.04 \%$, respectively. At the $40{ }^{\circ} \mathrm{C}$, $15450{ }^{\circ} \mathrm{C}$, and $60{ }^{\circ} \mathrm{C}$ loading conditions, $39 \%$ and $61 \%, 29 \%$ and $71 \%$, and $28 \%$ and $72 \%$ of the total data volume were 155 accounted for by the upper left and lower right data of the contours, respectively. From the $45^{\circ}$ contour map and the 156 average error calculation of the depth position of the surface layer, it can be observed that the points where the model 157 calculated value is higher than the measured value are mainly distributed in the higher temperature interval; that is, 158 the model calculated value in the upper depth region is slightly higher than the measured value. This is due to the 159 fact that the thermal boundary conditions of the upper surface of the calculated model do not consider heat loss during 160 the heating process, which produces differences with the actual indoor tests. With increasing depth, the effect of heat 161 loss gradually decreases, and the calculated error between the calculated and measured values gradually decreases. the indoor test was $0.1 \%-15 \%$, with an average error of $3.5 \%$, and the Pearson correlation coefficient was higher 164 than 0.8 under all conditions, which was a strong correlation result. The finite element model results correlate well 165 with the measured values of indoor tests, and the calculation results of the temperature change of the permeable 166 pavement in dry and water-holding states have high accuracy and good reproducibility of the temperature change 167 process, which provides a basis for the parameter setting of urban road paving models.

1682.3 Modeling of permeable pavement for urban roads

169 To study the factors influencing the cooling of the pavement of a permeable pavement structure of actual urban 170 roads and the difference in road surface temperature changes in different types of urban road pavements under 171 different water holding conditions, and to provide a reference for the design and optimization of permeable pavement 172 structures from the perspective of the road surface cooling behavior, three models of an urban road permeable 173 pavement structure with a width of $700 \mathrm{~cm}$ (standard width of two lanes) under actual solar radiation conditions were 
174 established, which are non-permeable, surface-permeable, and fully permeable pavement structures. The numerical

175 calculation of the road surface temperature change process and the solar radiation intensity change curve is presented

176 in Figure 4.

Table 2 .

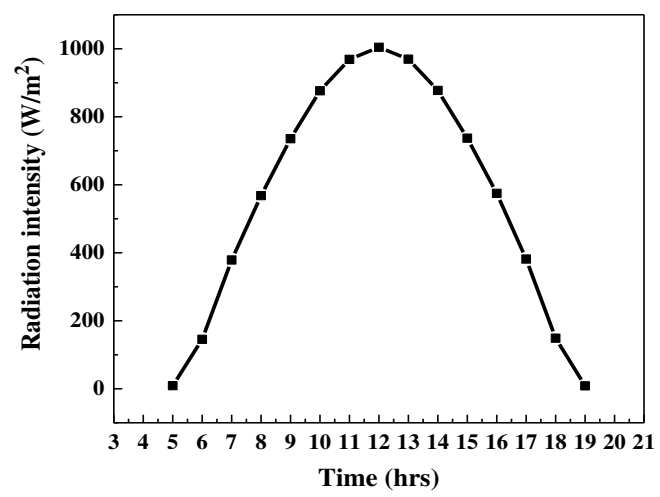

Figure 4 Daily variation curve of solar radiation intensity

The specifications of the material and thickness of the three road paving structures, A, B, and C, are listed in Table 2 Road paving type specifications

\begin{tabular}{ccccc}
\hline & & \multicolumn{3}{c}{ Model layers } \\
\cline { 3 - 5 } Pavement type & Parameters & Upper surface & Lower surface \\
course & course & Base course \\
Type A & & AC-13 & AC-13 & $\begin{array}{c}\text { cement stabilized } \\
\text { macadam }\end{array}$ \\
Non-permeable pavement & Material Type & 10 & 20 & 20 \\
\hline Type B & Mhickness (cm) & OGFC-13 & AC-13 & cement stabilized \\
Surface-permeable & Thickness (cm) & 10 & 20 & macadam \\
\hline pavement & Material Type & OGFC-13 & ATPB & graded broken \\
\hline Fully permeable pavement & Thickness (cm) & 10 & 20 & stone \\
\hline
\end{tabular}


capacity of $824 \mathrm{~J} /\left(\mathrm{kg} /{ }^{\circ} \mathrm{C}\right)$ and $853 \mathrm{~J} /\left(\mathrm{kg} /{ }^{\circ} \mathrm{C}\right)$. The ATPB type surface layer porosity was set to $22 \%$, with water holding

rate of $1.663 \%$ and dry and water holding state integrated specific heat capacity of $860 \mathrm{~J} /\left(\mathrm{kg} /{ }^{\circ} \mathrm{C}\right)$ and $915 \mathrm{~J} /\left(\mathrm{kg} /{ }^{\circ} \mathrm{C}\right)$.

The porosity of the base course cement-stabilized gravel mix was set to $5.1 \%$, with water-holding rate of $0.868 \%$ and

capacity of the dry and water-holding states was $850 \mathrm{~J} /\left(\mathrm{kg} /{ }^{\circ} \mathrm{C}\right)$ and $1010 \mathrm{~J} /\left(\mathrm{kg} /{ }^{\circ} \mathrm{C}\right)$, respectively. The variation in the

\section{Analysis of the factors influencing the cooling of a permeable pavement} conditions.

(1) Effect of thickness of the upper surface course

The thickness of the upper surface course of OGFC was set to $4,6,8,10$, and $12 \mathrm{~cm}$, the lower surface course was $20 \mathrm{~cm}$ ATPB material, the base course was $30 \mathrm{~cm}$ graded gravel material, and the thickness of the subgrade was $100 \mathrm{~cm}$.

(2) Effect of thickness of the lower surface course

The thickness of the upper surface course of OGFC was set to $5 \mathrm{~cm}$, the thickness of the lower surface course 
of ATPB was set to $10,15,20,25$, and $30 \mathrm{~cm}$, and the thickness of the base course and subgrade remained unchanged.

(3) Effect of thickness of the base course

The thickness of the upper surface course of OGFC was set to $5 \mathrm{~cm}$, the thickness of the lower surface course

remained unchanged. layer thickness parameters of the permeable pavement, as shown in Figure 5.

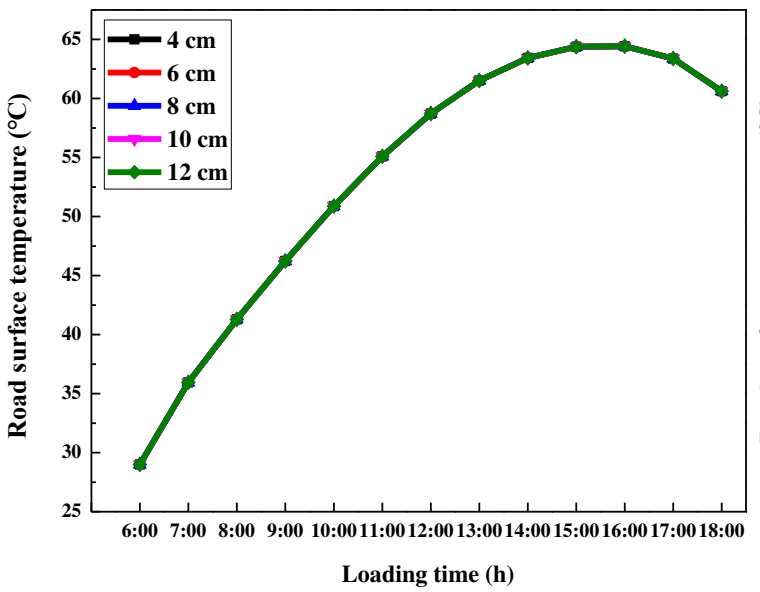

(a) Upper surface course

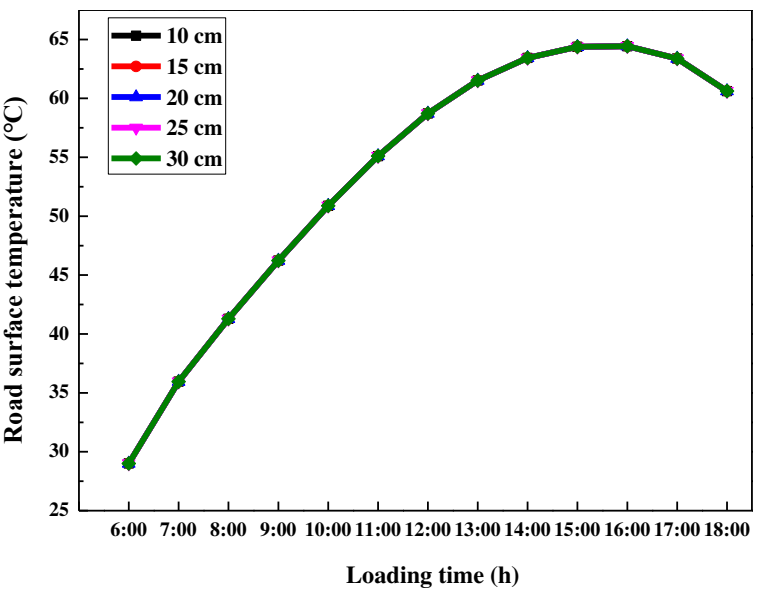

(b) Lower surface course

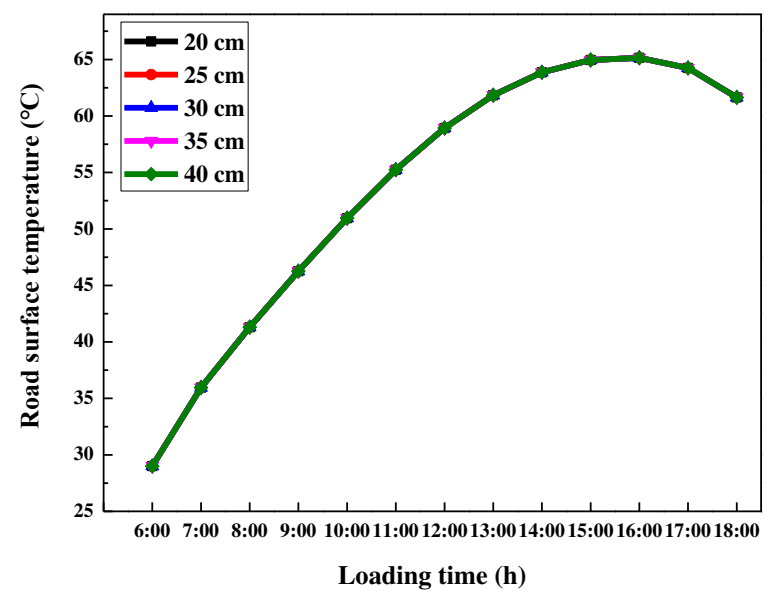

(c) Base course

Figure 5 Effect of thickness on the temperature of the permeable pavement surface

As can be observed from Figure 5, the trend of change in road surface temperature of the permeable pavement 
under each change in layer thickness is basically the same, and the road surface temperature change curves obtained

222 by changing the thickness parameters of the upper surface course, lower surface course, and base course overlap. The

223 calculation results of road surface temperature under different surface course and base course thicknesses are

224 basically the same. It can be observed that under the same environmental conditions, the structural layer thickness

225 parameters do not have a significant effect on the cooling effect of the permeable pavement road surface. From the

226 perspective of the design of permeable pavements, the thickness of the permeable pavement structure should be

227 determined according to the actual requirements of road bearing capacity and permeability performance.

$228 \quad 3.2$ Analysis of the effect of specific heat capacity parameters

To analyze the influence of the specific heat capacity parameters of different layers of a permeable pavement on

230 the surface temperature during the warming process, the values of specific heat capacity parameters of the upper

231 surface course, lower surface course, and base course of the permeable pavement were changed, and the change in

232 temperature of the road surface was compared under the same other conditions. The parameters of the permeable

233 paving model used were $5 \mathrm{~cm}$ OGFC-13 mix for the upper surface course, $20 \mathrm{~cm}$ ATPB mix for the lower surface

234 course, $40 \mathrm{~cm}$ graded gravel for the base course, and a $100 \mathrm{~cm}$ subgrade was set.

235 (1) Effect of specific heat capacity parameter of upper surface course

236 The specific heat capacity of the upper surface course of OGFC was set to 800, 900, 1000, 1100, and 1200

$237 \mathrm{~J} /\left(\mathrm{kg} /{ }^{\circ} \mathrm{C}\right)$, and the other parameters remained unchanged.

238 (2) Influence of specific heat capacity parameter of the lower surface course

239 The specific heat capacity of the lower surface course of ATPB was set to 800, 900, 1000, 1100, and 1200

$240 \mathrm{~J} /\left(\mathrm{kg} /{ }^{\circ} \mathrm{C}\right)$, and the other parameters remained unchanged.

241 (3) Influence of specific heat capacity parameter of the base course 
243 the other parameters remained unchanged.

244 Under the above parameters, the numerical calculation of the road surface temperature under actual loading 245 conditions for $12 \mathrm{~h}$ was carried out, and the change curve of the road surface temperature with loading time was 246 plotted under the change in specific heat capacity parameters of the different layers of the permeable pavement. The results are shown in Figure 6.

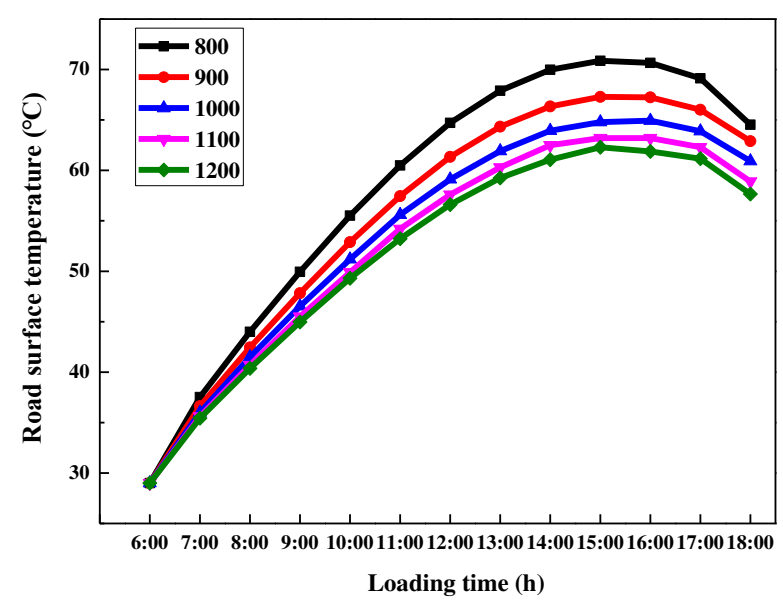

(a) Upper surface course

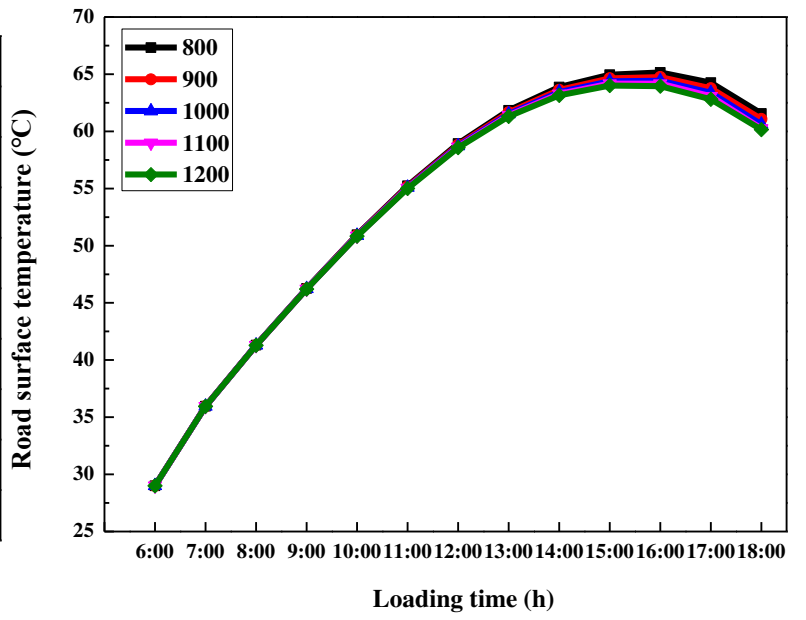

(b) Lower surface course

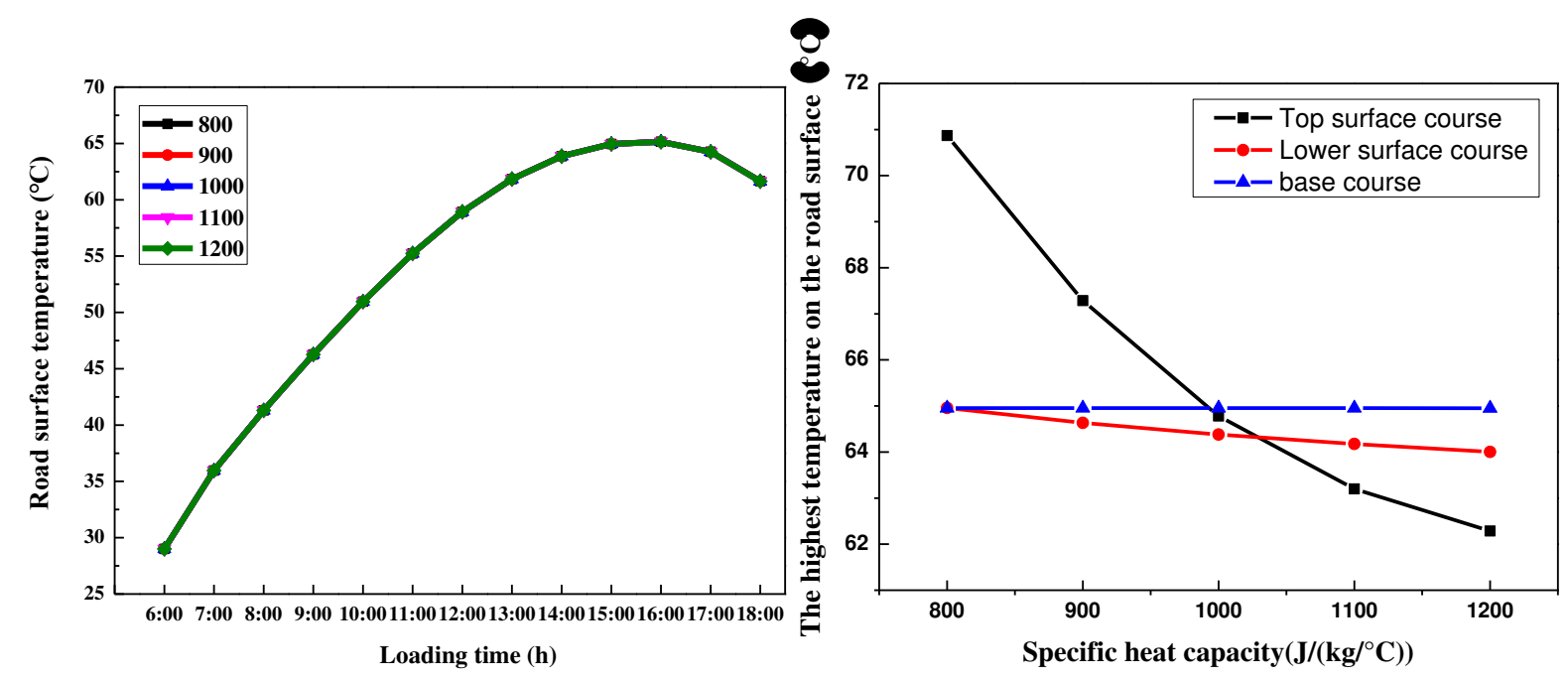

(c) Base course

(d) Maximum surface temperature of the road on a day Figure 6 Effect of specific heat capacity on the temperature of permeable pavement surface

From Figure 6, it can be observed that the change in specific heat capacity of the upper surface course has a 
of $8.5{ }^{\circ} \mathrm{C}$ at the highest point and $6.9{ }^{\circ} \mathrm{C}$ after the loading is completed. For every $100 \mathrm{~J} /\left(\mathrm{kg} /{ }^{\circ} \mathrm{C}\right)$ increase in the specific heat capacity of the upper surface course material, the maximum daily temperature of the road surface can be reduced by approximately $2.1^{\circ} \mathrm{C}$. The change in the specific heat capacity of the lower surface course material has a low impact on the road surface temperature, with a maximum temperature difference of $1.4{ }^{\circ} \mathrm{C}$. For every 100 $\mathrm{J} /\left(\mathrm{kg} /{ }^{\circ} \mathrm{C}\right)$ increase in the specific heat capacity of the material, the temperature decreases by approximately $0.4{ }^{\circ} \mathrm{C}$, which is significantly lower than the upper surface course results. For the base course, the change in specific heat capacity at this location has almost no effect on the road surface temperature. As can be observed from Figure 8(d), the maximum daily road surface temperature decreases with an increase in the specific heat capacity of the upper surface course and the lower surface course, the trend gradually becomes slower, and the influence on the road surface temperature gradually decreases. In summary, the change in the specific heat capacity of the upper surface course of

a permeable pavement has a more significant effect on the temperature of the permeable pavement surface, and the degree of influence gradually decreases with increasing depth.

3.3 Analysis of the influence of thermal conductivity parameters

conductivity parameters of the upper surface course, lower surface course, and base course of the permeable pavement were changed to compare the change in temperature of the road surface. The model was a $5 \mathrm{~cm}$ OGFC mix

272 for the upper surface course, $20 \mathrm{~cm}$ ATPB mix for the lower surface course, $40 \mathrm{~cm}$ graded gravel for the base course, and a $100 \mathrm{~cm}$ subgrade was set.

(1) Influence of thermal conductivity parameters of the upper surface course 
the other parameters remained unchanged.

(2) Influence of thermal conductivity parameters of the lower surface course and the other parameters remained unchanged.

parameters remained unchanged.

pavement by changing the thermal conductivity parameters were plotted, and the results are shown in Figure 7.

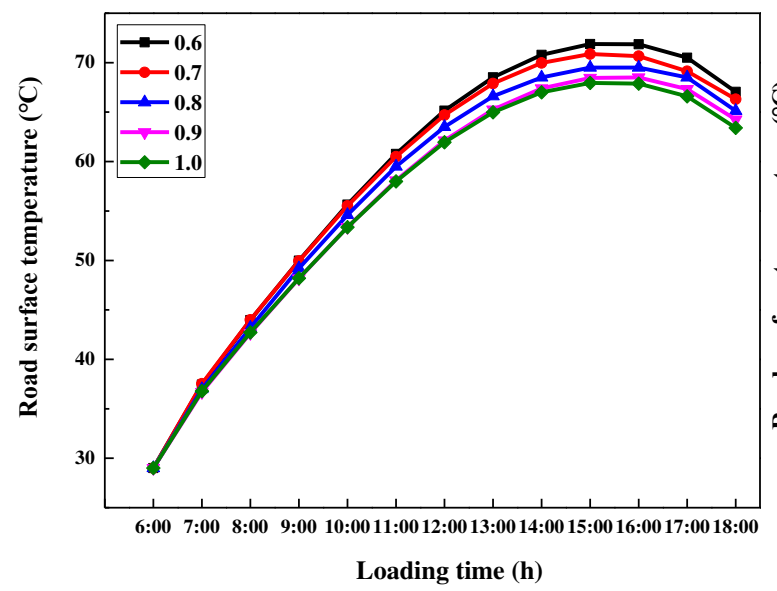

(a) Upper surface course

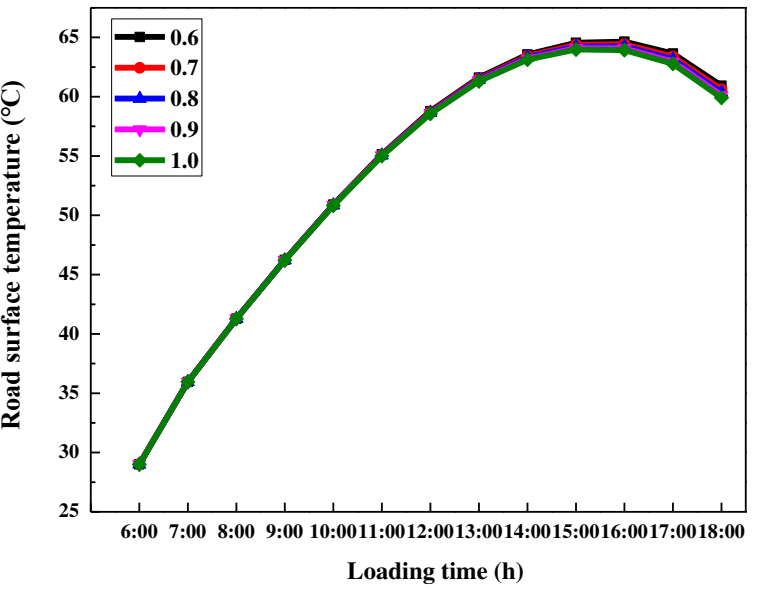

(b) Lower surface course 

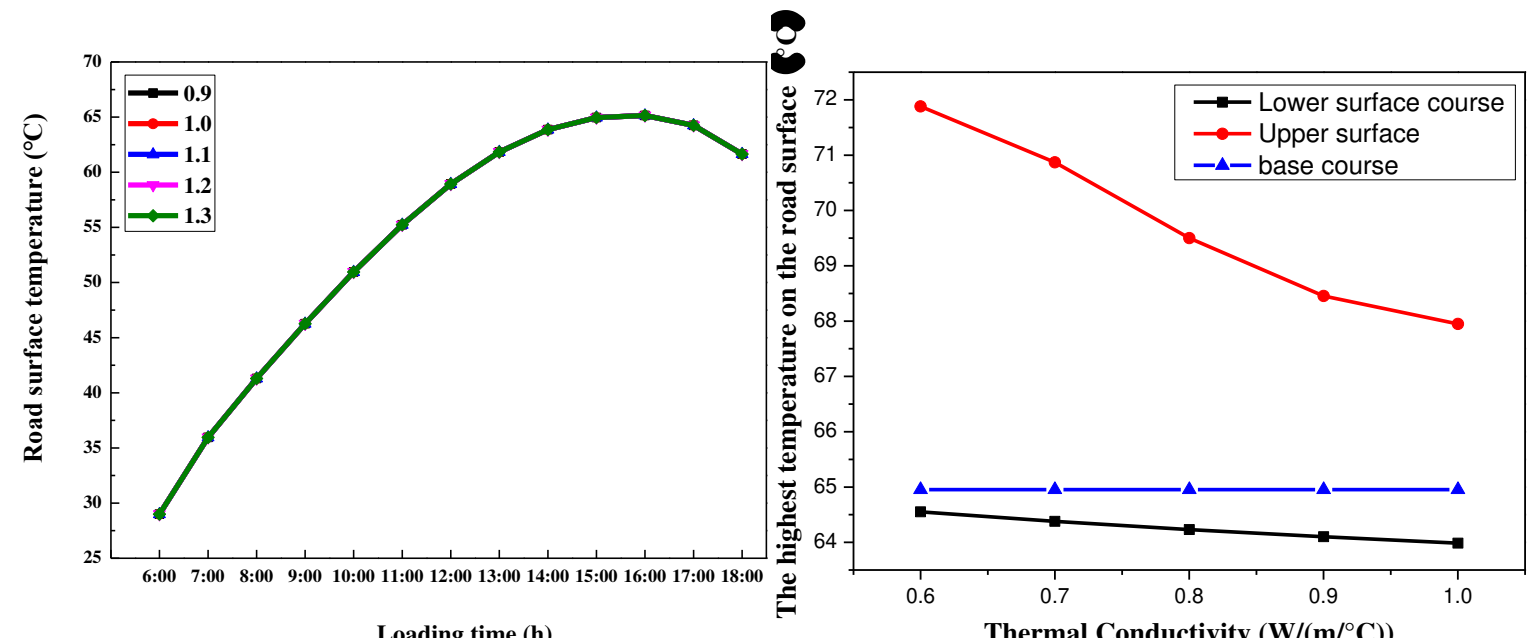

(c) Base course

(d) Maximum surface temperature of the road on a day

Figure 7 Effect of thermal conductivity on the temperature of permeable pavement surface

As can be observed from Figure 7, the change in thermal conductivity of the upper surface course has a

significant effect on the temperature change of the permeable pavement surface, with a temperature difference of

increase in the thermal conductivity of the material, the maximum daily temperature of the road surface is reduced

by approximately $0.9^{\circ} \mathrm{C}$. The degree of influence of the change in thermal conductivity within the lower surface

course structure on the road surface temperature is relatively low, whereas the change in thermal conductivity of the

subgrade has almost no influence on the road surface temperature. It can be observed that the effect of the change in

thermal conductivity on the cooling effect of the permeable pavement surface decreases gradually with an increase in the depth of the structure. As can be found from Figure 9(d), the maximum daily road surface temperature decreases with an increase in the thermal conductivity of the upper surface course and the lower surface course, the trend gradually becomes slower, and the influence on the road surface temperature gradually decreases.

From the perspective of permeable pavement material parameters, an upper layer with a larger specific heat capacity or thermal conductivity of the material, or the use of modified materials and additives to change the comprehensive specific heat capacity or thermal conductivity of the material, can result in better cooling effect on 


\section{Analysis of cooling effect of the permeable pavement surface}

312 To analyze the differences in the road surface temperature changes of different urban road pavements, the non-

313 permeable, surface-permeable, and fully permeable pavement types in the dry state were recorded as Ad, Bd, Cd, and

314 those in the water-holding state were recorded as $\mathrm{Aw}, \mathrm{Bw}, \mathrm{Cw}$. The road surface temperature changes during $12 \mathrm{~h}$ in

315 the dry and water-holding states were calculated to analyze the effects of road pavement types and dry and wet states

316 on the road surface temperature.

317 4.1 Comparison of road surface temperature in dry and water-holding condition

318 To analyze the difference in surface temperature during the warming process of the three pavement structures

319 under dry and water-holding conditions, and to compare the changes in the temperature data of different pavement 


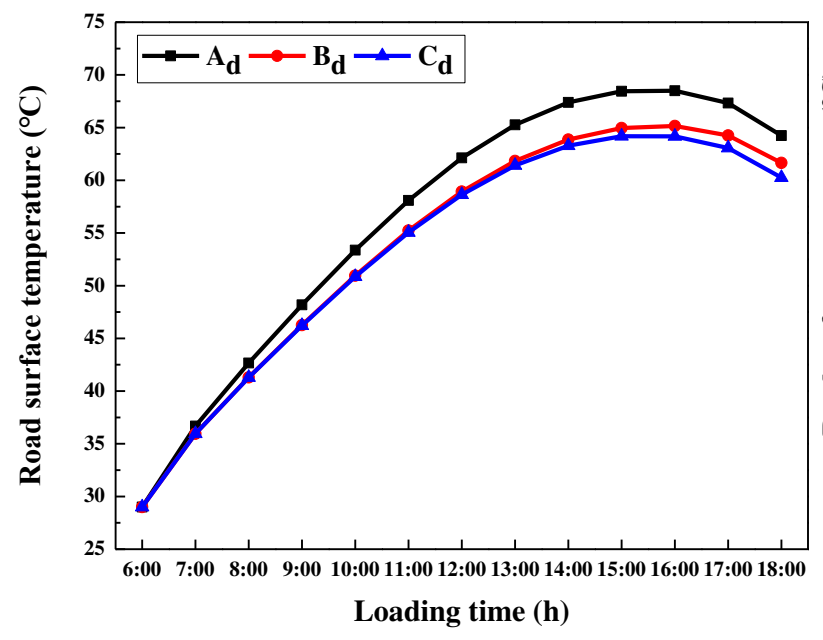

(a) Dry condition

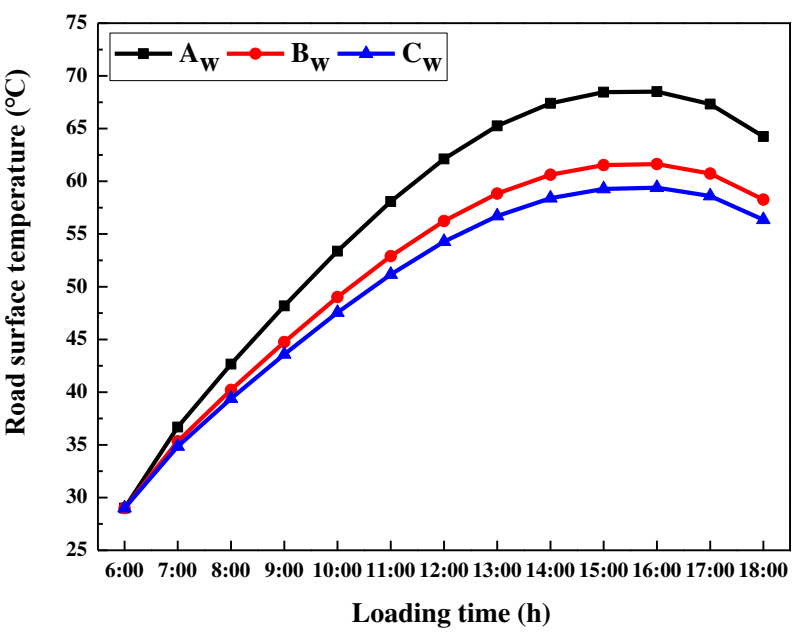

(b) Water-holding condition

Figure 8 Comparison of road surface temperatures in dry and water-holding conditions

As can be observed from Figure 8(a), the temperature of the non-permeable road surface during the warming

process in the dry state is significantly higher than that of the permeable pavement, and the maximum daily temperature of the road surface of type $\mathrm{A}$ is $3.4{ }^{\circ} \mathrm{C}$ and $4.3{ }^{\circ} \mathrm{C}$ higher than those of types $\mathrm{B}$ and $\mathrm{C}$, respectively, and

$2.6{ }^{\circ} \mathrm{C}$ and $3.9{ }^{\circ} \mathrm{C}$ higher than those of types $\mathrm{B}$ and $\mathrm{C}$ at the end of warming. The maximum daily road surface temperature of the surface-permeable pavement is approximately $1.3{ }^{\circ} \mathrm{C}$ higher than that of a fully permeable structure. Under dry conditions, the difference in road surface temperature is mainly reflected in the non-permeable and permeable pavements, and the trend of changes in road surface temperature with time is the same for the three pavement structures.

As can be observed from Figure 8(b), during the warming process of the non-permeable road pavement in the holding water state, the road surface temperature is significantly higher than that of permeable pavement. The maximum daily road surface temperatures of type A are $5.8{ }^{\circ} \mathrm{C}$ and $8.1{ }^{\circ} \mathrm{C}$ higher than those of types $\mathrm{B}$ and $\mathrm{C}$, respectively, and $5.7{ }^{\circ} \mathrm{C}$ and $7.8^{\circ} \mathrm{C}$ higher than those of types $\mathrm{B}$ and $\mathrm{C}$ at the end of warming. The maximum daily road surface temperature of the surface-permeable pavement is approximately $2{ }^{\circ} \mathrm{C}$ higher than that of a fully permeable structure, and its temperature can be approximately $1.8^{\circ} \mathrm{C}$ higher at the end of the warming and loading 


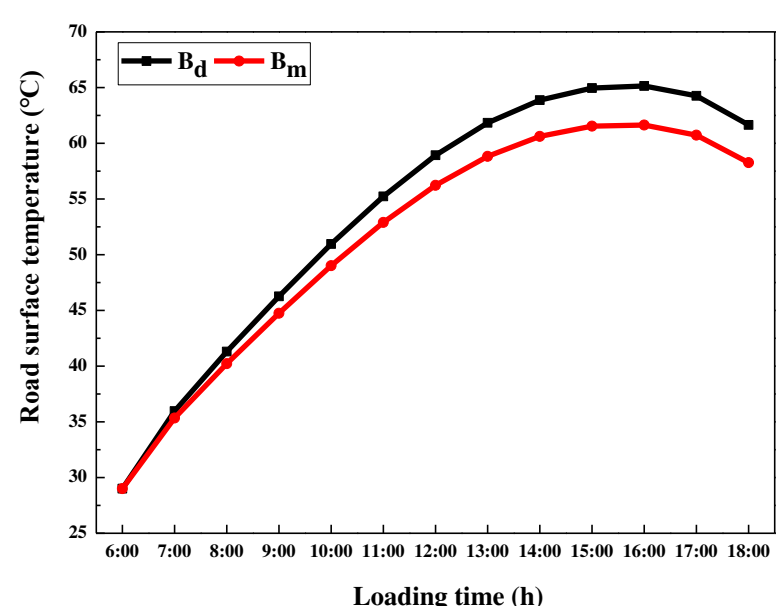

(a) Surface-permeable type structure

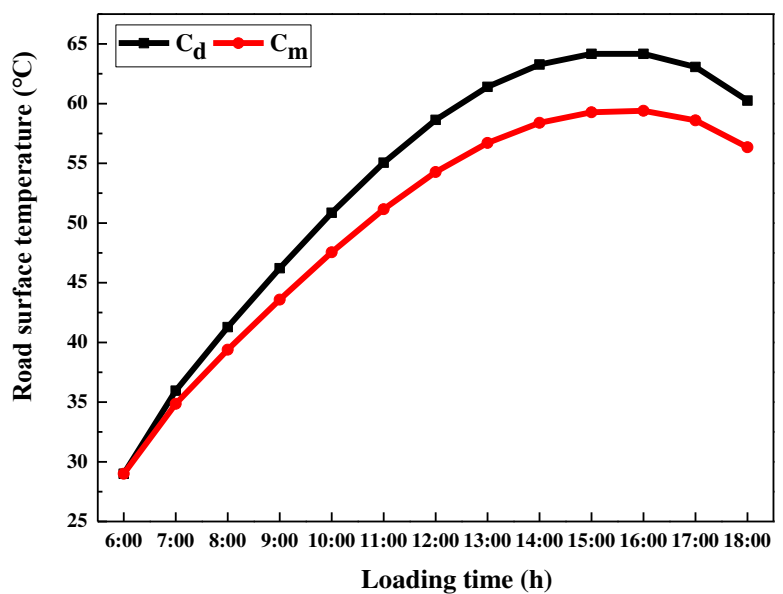

(b) Fully permeable structure

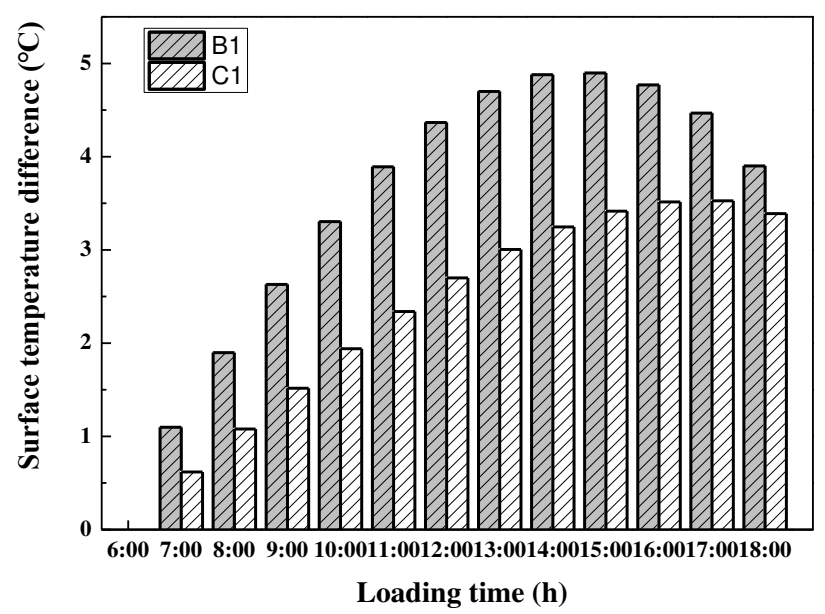

From Figure 9, it can be observed that the trend of temperature change of permeable pavement types B and C 
under dry and water-holding conditions is basically the same. The class B surface-permeable pavement has a maximum daily road surface temperature difference of $3.5{ }^{\circ} \mathrm{C}$ between the dry and wet conditions and $3.4{ }^{\circ} \mathrm{C}$ after between the dry and wet conditions and $3.9^{\circ} \mathrm{C}$ after loading is completed. Because of the different levels of permeable layers, the effect of water retention on the cooling effect of each type of permeable pavement is slightly different, and the effect of water retention of the surface layer permeable pavement on the road surface cooling is relatively weaker than that of the fully permeable type of pavement. From the perspective of permeable pavement structure type, a fully permeable pavement structure has an excellent road surface cooling effect.

\section{Conclusion}

This paper provides reference suggestions for the optimization of permeable pavement surface cooling from

three perspectives: design, material parameters, and structure type, with the following main conclusions:

(1) Under the same environmental conditions, it is difficult to influence the road surface temperature of a permeable pavement by changing the thickness of each structural layer, and the structural layer thickness parameter does not have a significant effect on the cooling effect of the road surface.

(2) The change in the specific heat capacity of the upper surface course of a permeable pavement has a more significant effect on the temperature of the permeable pavement surface, and the degree of influence gradually decreases with increasing depth. For every $100 \mathrm{~J} /\left(\mathrm{kg} /{ }^{\circ} \mathrm{C}\right)$ increase in specific heat capacity of the upper and lower surface courses, the maximum daily road surface temperature can be reduced by approximately $2.1{ }^{\circ} \mathrm{C}$ and $0.4{ }^{\circ} \mathrm{C}$, respectively, under the same warming environment.

(3) The effect of change in thermal conductivity on the cooling effect of a permeable pavement surface 
surface course of the structure near the surface of the road has a relatively high degree of influence on the cooling effect of the road surface. For every $0.1 \mathrm{~W} /\left(\mathrm{m} /{ }^{\circ} \mathrm{C}\right)$ increase in thermal conductivity of the upper and lower layers, the maximum daily road surface temperature can be reduced by approximately $0.9^{\circ} \mathrm{C}$ and $0.2{ }^{\circ} \mathrm{C}$, respectively.

(4) Under the same warming environment, the maximum daily road surface temperature of the surfacepermeable and fully permeable pavements in the dry state can be reduced by approximately $3.4{ }^{\circ} \mathrm{C}$ and $4.3{ }^{\circ} \mathrm{C}$ compared to non-permeable pavement, and can be reduced by approximately $5.8{ }^{\circ} \mathrm{C}$ and $8.1{ }^{\circ} \mathrm{C}$, respectively, in the water-holding state. The maximum daily road surface temperatures in the dry and water-holding states of the fully permeable pavement can be reduced by approximately $1.3{ }^{\circ} \mathrm{C}$ and $1.8^{\circ} \mathrm{C}$, respectively, compared with those of the surface-permeable pavement, and the cooling effect is better than that of the surface-permeable pavement.

\section{Declarations :}

Acknowledgements: This article was funded by the Shaanxi Province Science Foundation of China (No. 2020JM251), the Fundamental Research Funds for the Central Universities (300102210211)).

Data availability: The datasets used and analyzed during the current study are available from the corresponding author on reasonable request.

\section{References}

Booth DB, Leavitt J (1999) Field Evaluation of Permeable Pavement Systems for Improved Stormwater Management Journal of the American Planning Association 65

Chen Y-C, Chiu H-W, Su Y-F, Wu Y-C, Cheng K-S (2017) Does urbanization increase diurnal land surface temperature variation? Evidence and implications Landscape and Urban Planning 157:247-258 doi:10.1016/j.landurbplan.2016.06.014

Fu J (2011) Temperature reduction performance of porous asphalt pavement considering heat convection China Civil Engineering Journal 44:138-142 (in Chinese)

Haselbach L, Boyer M, Kevern JT, Schaefer VR (2011) Cyclic Heat Island Impacts on Traditional versus Pervious Concrete Pavement Systems Transportation Research Record 2240

Hongshan W (2017) Characteristics of runoff pollutants purification and temperature reduction for porous asphalt pavement. Harbin Institute of Technology, Road and Railway Engineering

Hou L et al. (2020) Study on Variation of Surface Runoff and Soil Moisture Content in the Subgrade of Permeable Pavement Structure Advances in Civil Engineering 2020:1-12 doi:10.1155/2020/8836643 
Hui W, Li-ping L, Xiao-fei G, Li-jun S, (2012) Performance of OGFC mixtures using warm mix technology Journal of Building Materials 15:427-429+434 (in Chinese)

Ikechukwu EE (2015) The Effects of Road and Other Pavement Materials on Urban Heat Island (A Case Study of Port Harcourt City) Journal of Environmental Protection 6

Kuang X, Sansalone J, Ying G, Ranieri V (2010) Pore-structure models of hydraulic conductivity for permeable pavement Journal of Hydrology 399

Li H, Harvey J, Ge Z (2014) Experimental investigation on evaporation rate for enhancing evaporative cooling effect of permeable pavement materials Construction and Building Materials 65

Li H, Harvey J, Jones D (2013a) Cooling Effect of Permeable Asphalt Pavement under Dry and Wet Conditions Transportation Research Record 2372

Li H, Harvey JT, Holland TJ, Kayhanian M (2013b) Corrigendum: The use of reflective and permeable pavements as a potential practice for heat island mitigation and stormwater management Environmental Research Letters 8

Li H, He Y, Harvey J (2016) Human Thermal Comfort: Modeling the Impact of Different Cool Pavement Strategies Transportation Research Record 2575

Li Q, Wang F, Yu Y, Huang Z, Li M, Guan Y (2019) Comprehensive performance evaluation of LID practices for the sponge city construction: A case study in Guangxi, China Journal of Environmental Management 231

Liu Y, Li T, Peng H (2018) A new structure of permeable pavement for mitigating urban heat island Science of The Total Environment 634:1119-1125

Nakayama T, Fujita T (2010) Cooling effect of water-holding pavements made of new materials on water and heat budgets in urban areas Landscape and Urban Planning 96

Nemirovsky EM, Welker AL, Lee R (2013) Quantifying Evaporation from Pervious Concrete Systems: Methodology and Hydrologic Perspective Journal of Irrigation and Drainage Engineering 139

Niu ZG, Lv ZW, Zhang Y, Cui ZZ (2016) Stormwater infiltration and surface runoff pollution reduction performance of permeable pavement layers Environ Sci Pollut Res Int 23:2576-2587 doi:10.1007/s11356-015-5466-7

Palla A, Gnecco I, Carbone M, Garofalo G, Lanza LG, Piro P (2015) Influence of stratigraphy and slope on the drainage capacity of permeable pavements: laboratory results Urban water journal 12:394-403

Roseen RM, Ballestero TP, Houle JJ, Avellaneda P, Briggs J, Fowler G, Wildey R (2009) Seasonal Performance Variations for Storm-Water Management Systems in Cold Climate Conditions Journal of Environmental Engineering 135

Sun Y, Gao C, Li J, Wang R, Liu J (2019) Evaluating urban heat island intensity and its associated determinants of towns and cities continuum in the Yangtze River Delta Urban Agglomerations Sustainable Cities and Society 50

Wang J, Meng Q, Tan K, Zhang L, Zhang Y (2018) Experimental investigation on the influence of evaporative cooling of permeable pavements on outdoor thermal environment Building and Environment 140:184-193 doi:10.1016/j.buildenv.2018.05.033

Wei J, Aimin SHA, Jingjing X, Jianzhong PEI, Aimin SHA, Jingjing X, Jianzhong PEI (2013) Water storage-infiltration model for permeable asphalt pavement and its efficiency Journal of Tongji University (Natural Science) 41:72-77 (in Chinese)

Williamson RH Effects of environment on pavement temperatures. In: Intl Conf Structural Design Proc, 1972.

Yan-xia CAI, Ai-qin S, Yin-chuan GUO, De-qiang W (2015) Dynamic water damage behavior and dynamic seepage test for asphalt mixture Journal of Changan University (Natural Science Edition) 35:13-18+25 (in Chinese)

Zhou Y, Wang L, Liu J, Li W, Zheng Y (2012) Options of sustainable groundwater development in Beijing Plain, China Physics and Chemistry of the Earth 47-48

\section{Author information:}




\section{Affiliations}

444 Key Laboratory for Special Area Highway Engineering of Ministry of Education, Chang'an University, Xi’an,

\section{Shaanxi 710064, China}

446 Zhe Liu, Yuxiang Tian, Biao Ma, Wei Si, Xiaoqing Wang

\section{Contributions}

448 Zhe liu: conceptualization, methodology, software, data curation, writing — original draft preparation.

449 Yuxiang Tian: methodology, investigation, writing—reviewing, and editing.

450 Biao Ma: supervision, writing—reviewing, and editing.

451 Wei Si: supervision, writing—reviewing, and editing.

452 Xiaoqing Wang: investigation, writing — reviewing, and editing.

453 Corresponding author

454 Correspondence to Biao Ma.

455 Ethics declarations:

456 Ethics approval and consent to participate

457 Not applicable.

458 Consent for publication

459 Not applicable.

460 Competing interests

461 The authors declare that they have no competing interests. 


\section{Figures}
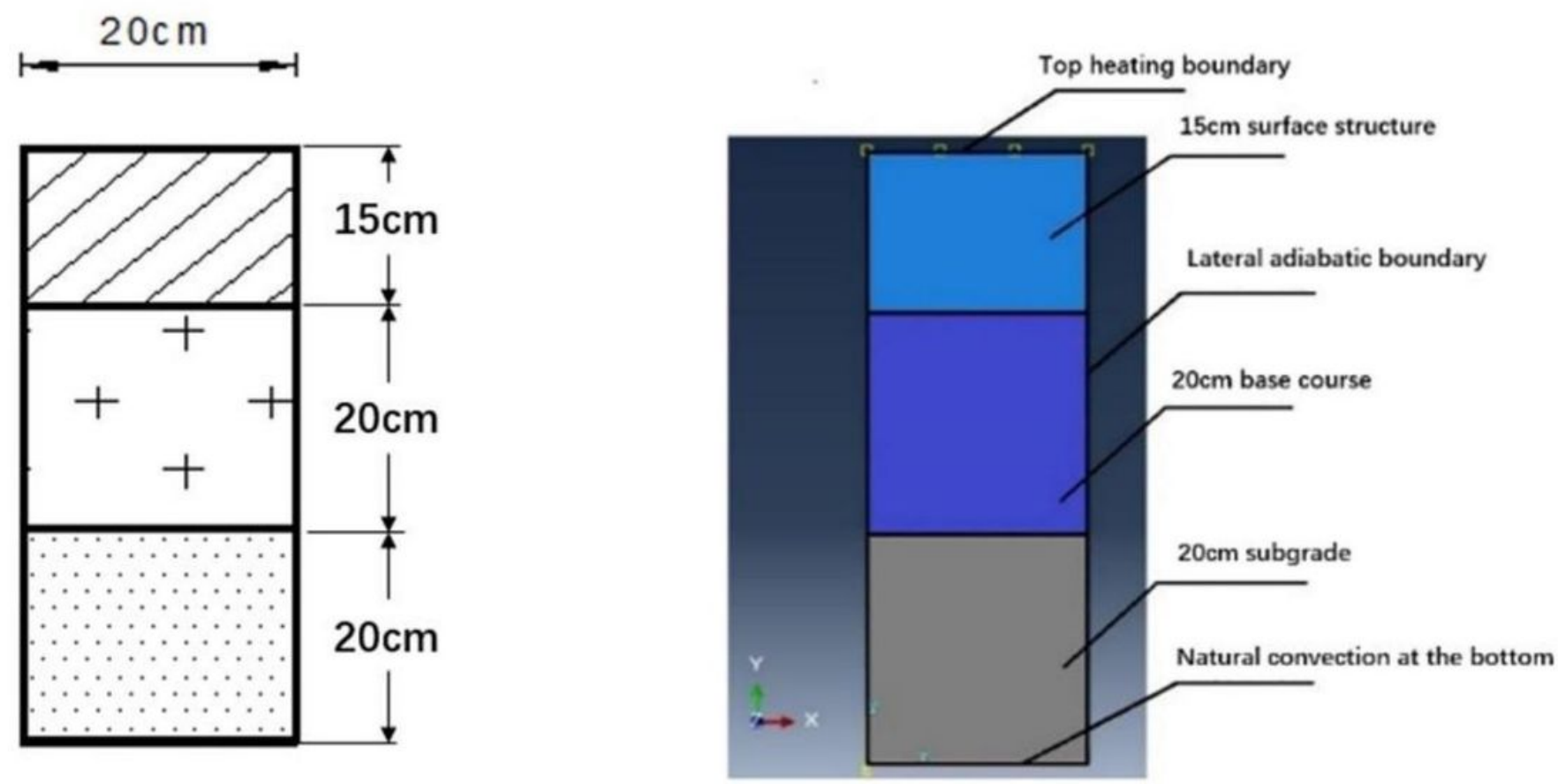

(a) Indoor test plane 2-D model (b) Numerical calculation 2-D model

\section{Figure 1}

Schematic of indoor test and numerical calculation model
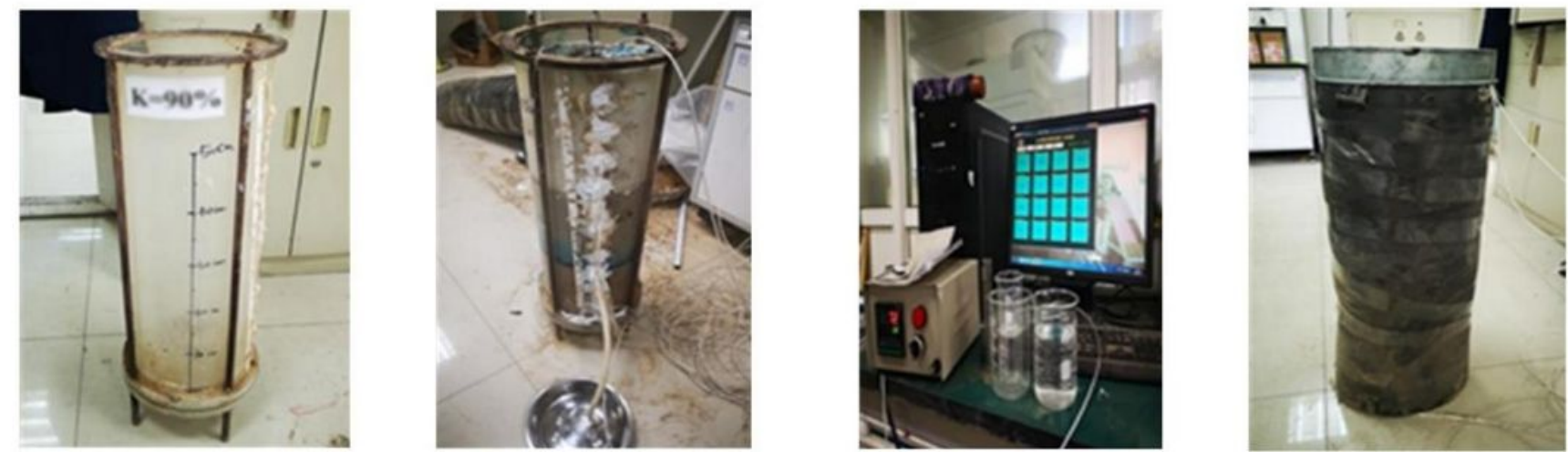

(a) Permeable paving test bucket (b) Temperature sensor and drain pipe (c) Intelligent temperature control equipment (d) Model insulation wrap

Figure 2

Indoor test model of permeable pavement 


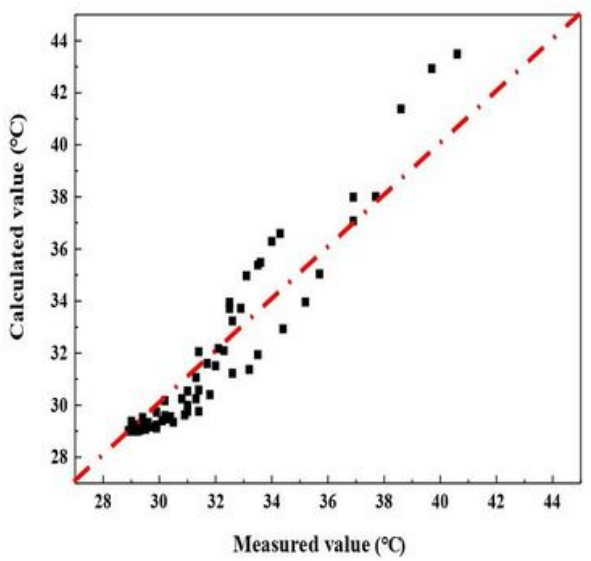

(a) $45^{\circ}$ contour plot at $40^{\circ} \mathrm{C}$

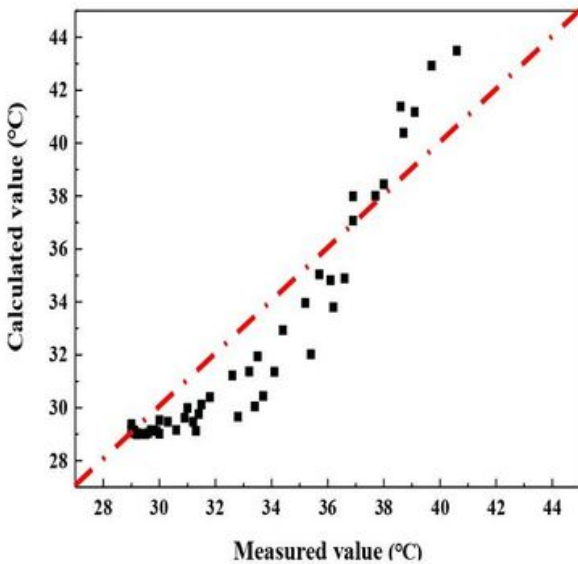

(b) $45^{\circ}$ contour plot at $50^{\circ} \mathrm{C}$

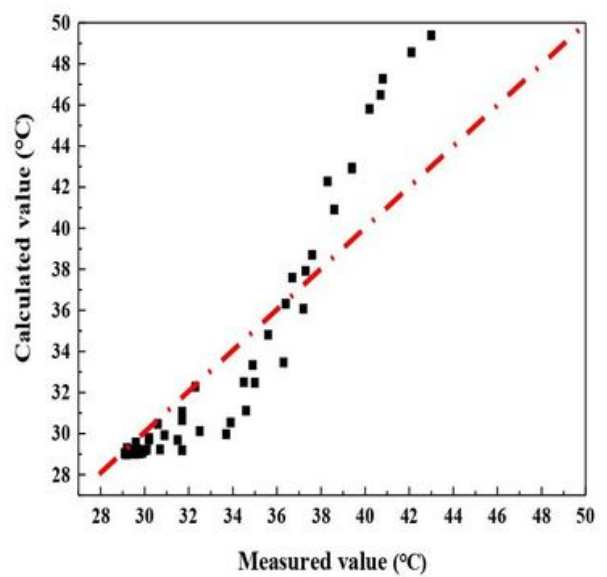

(c) $45^{\circ}$ contour plot at $60^{\circ} \mathrm{C}$

Figure 3

$45^{\circ}$ contour plot of measured and calculated values at $40-60{ }^{\circ} \mathrm{C}$

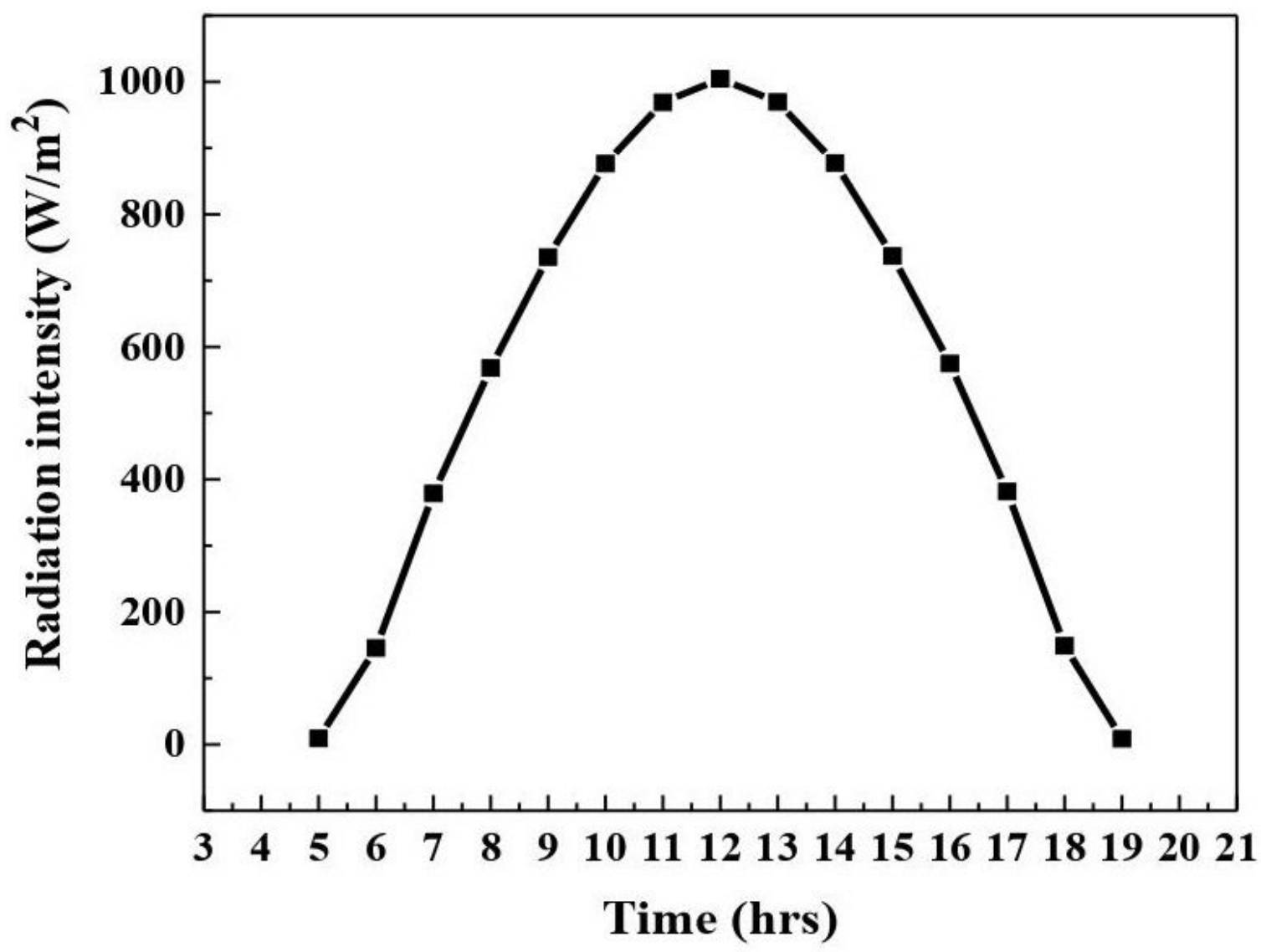

Figure 4

Daily variation curve of solar radiation intensity 


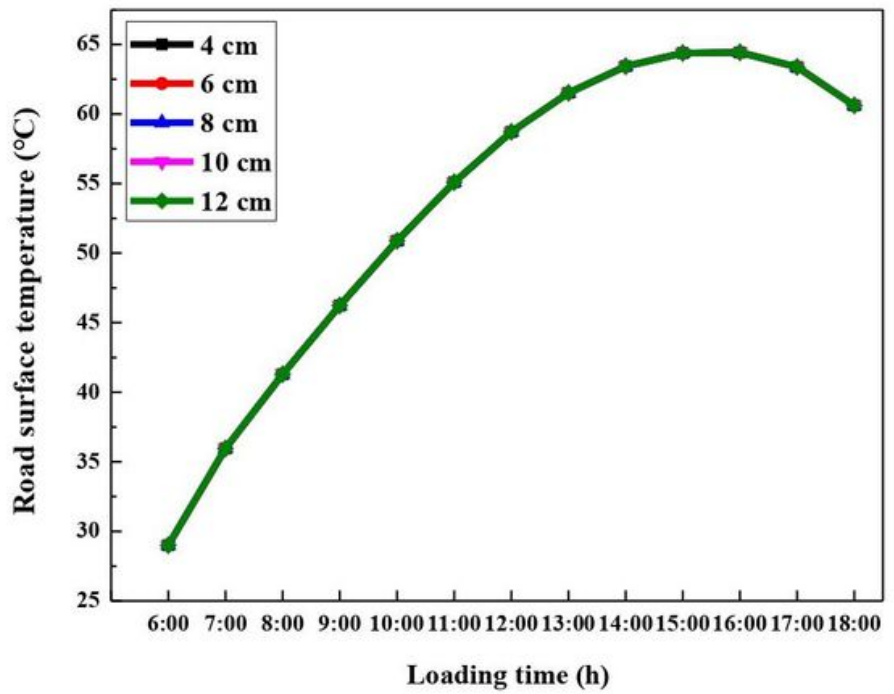

(a) Upper surface course

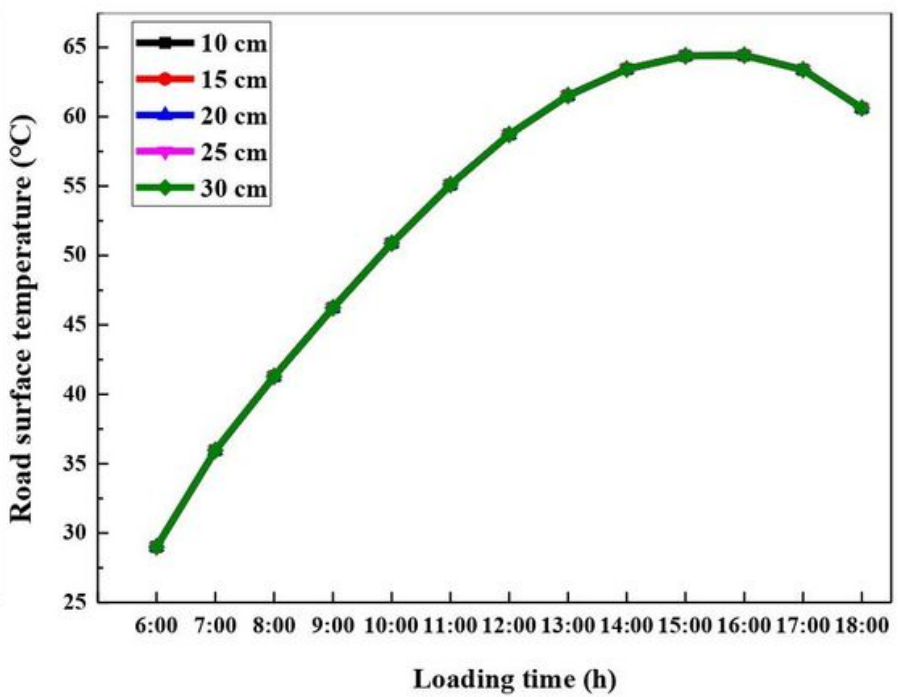

(b) Lower surface course

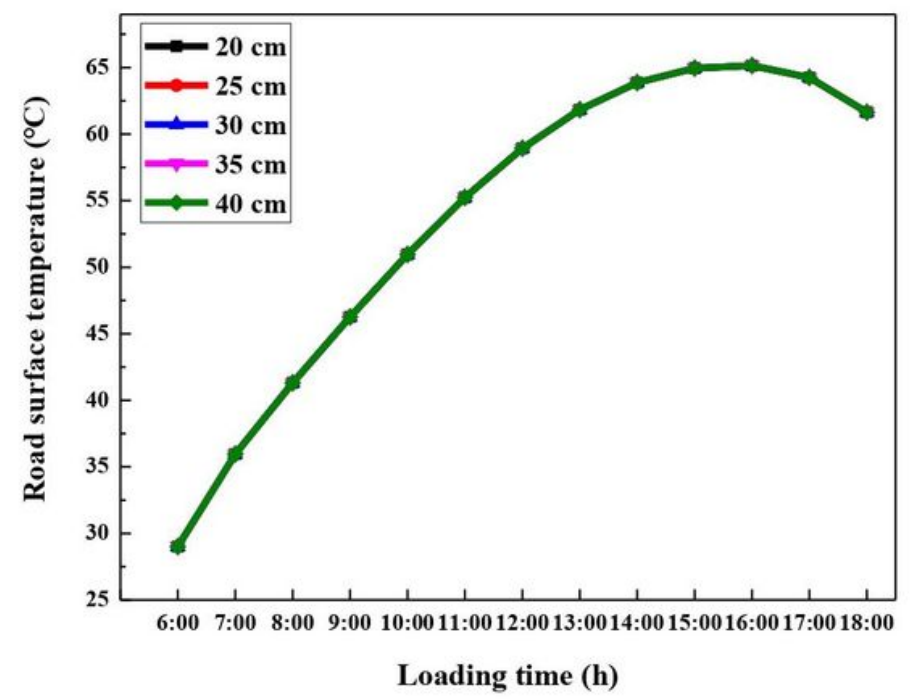

(c) Base course

\section{Figure 5}

Effect of thickness on the temperature of the permeable pavement surface 


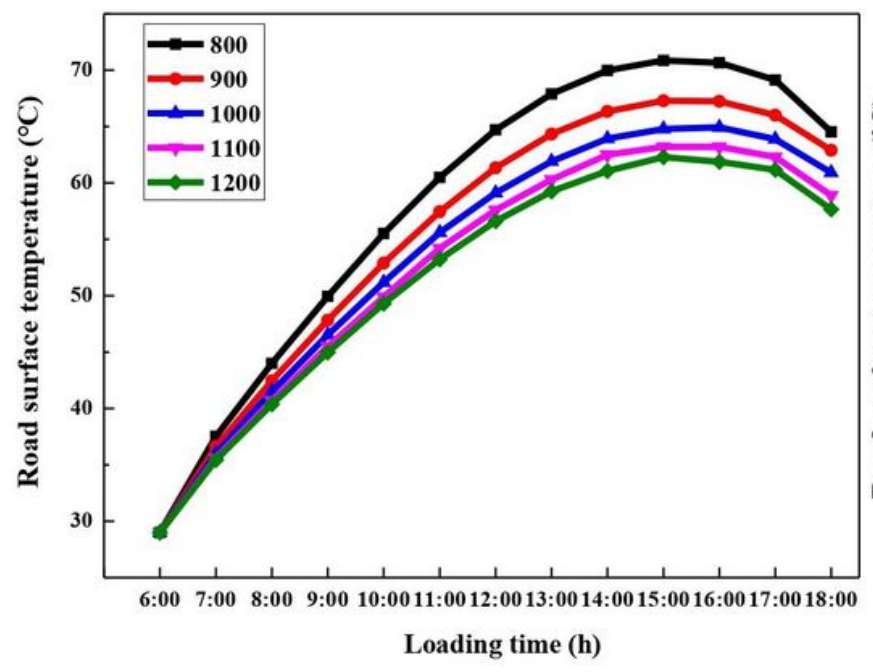

(a) Upper surface course

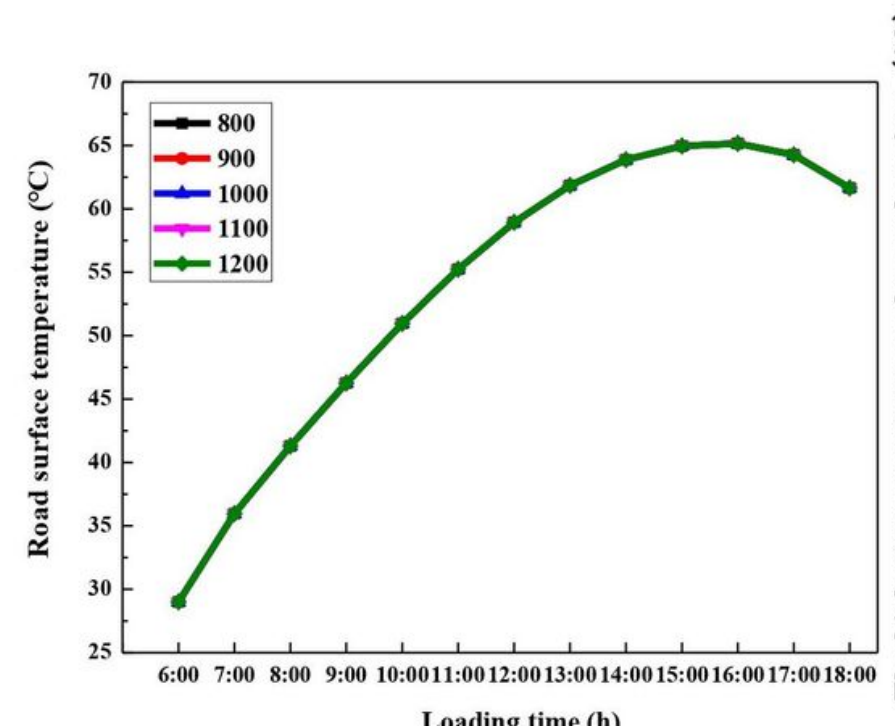

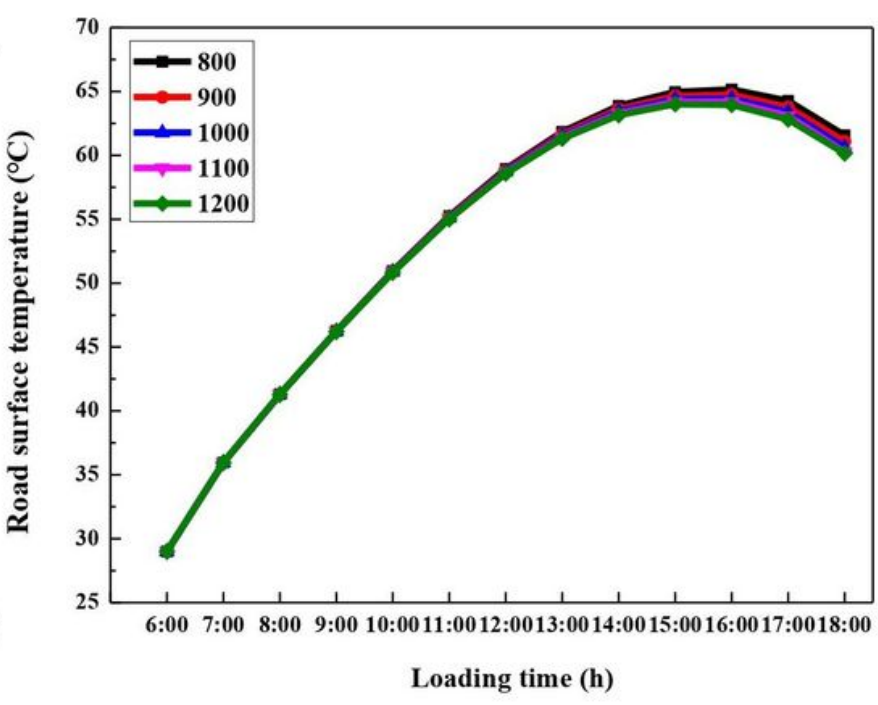

(b) Lower surface course

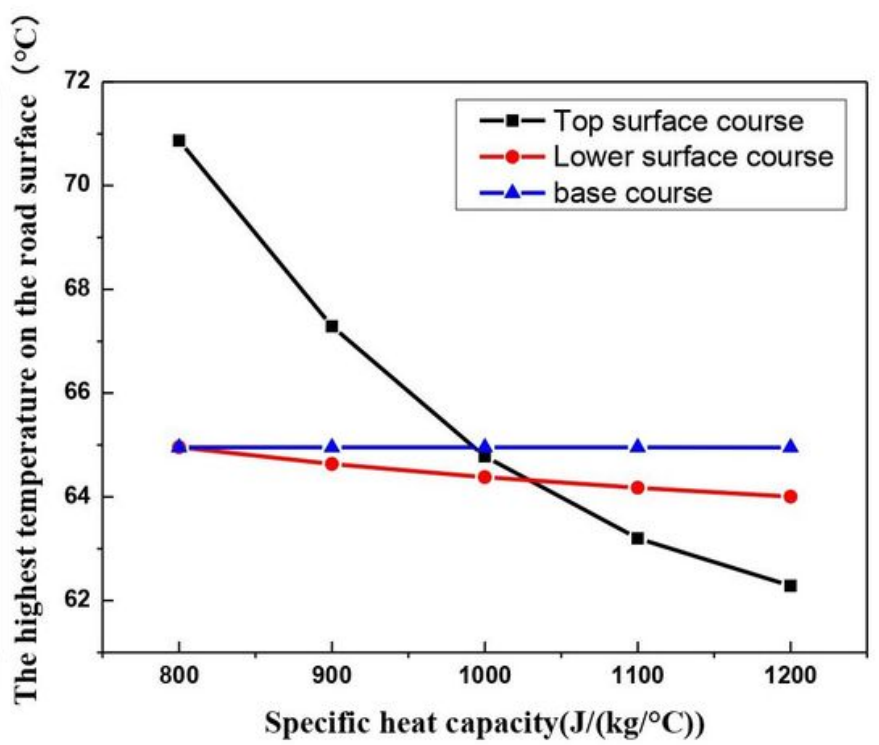

(d) Maximum surface temperature of the road on a day

\section{Figure 6}

Effect of specific heat capacity on the temperature of permeable pavement surface 


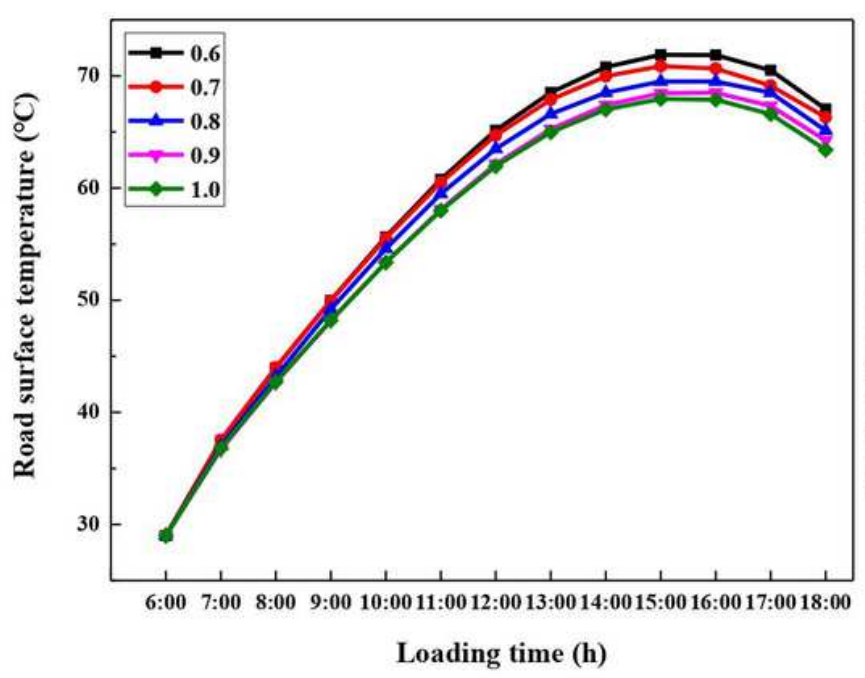

(a) Upper surface course

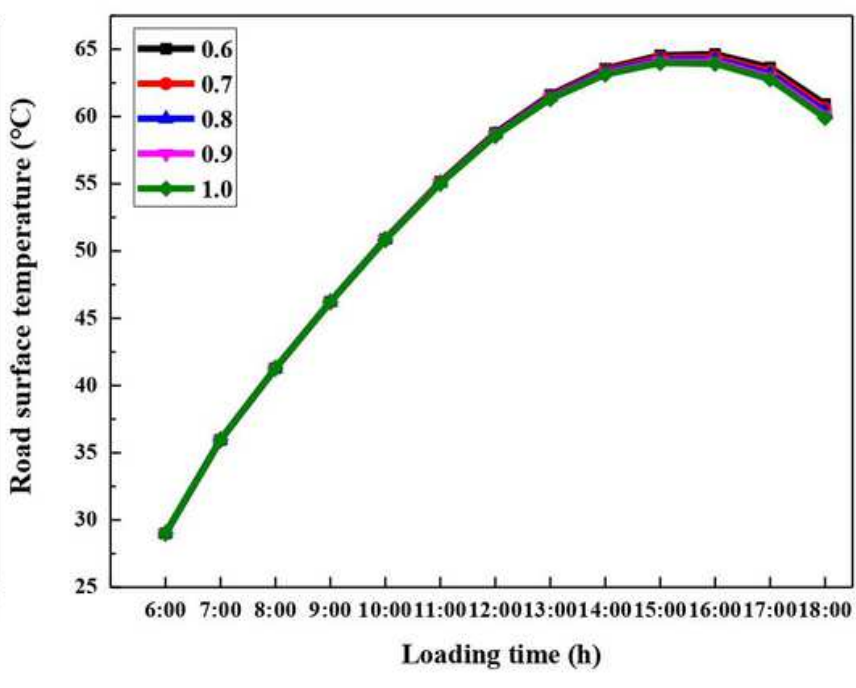

(b) Lower surface course
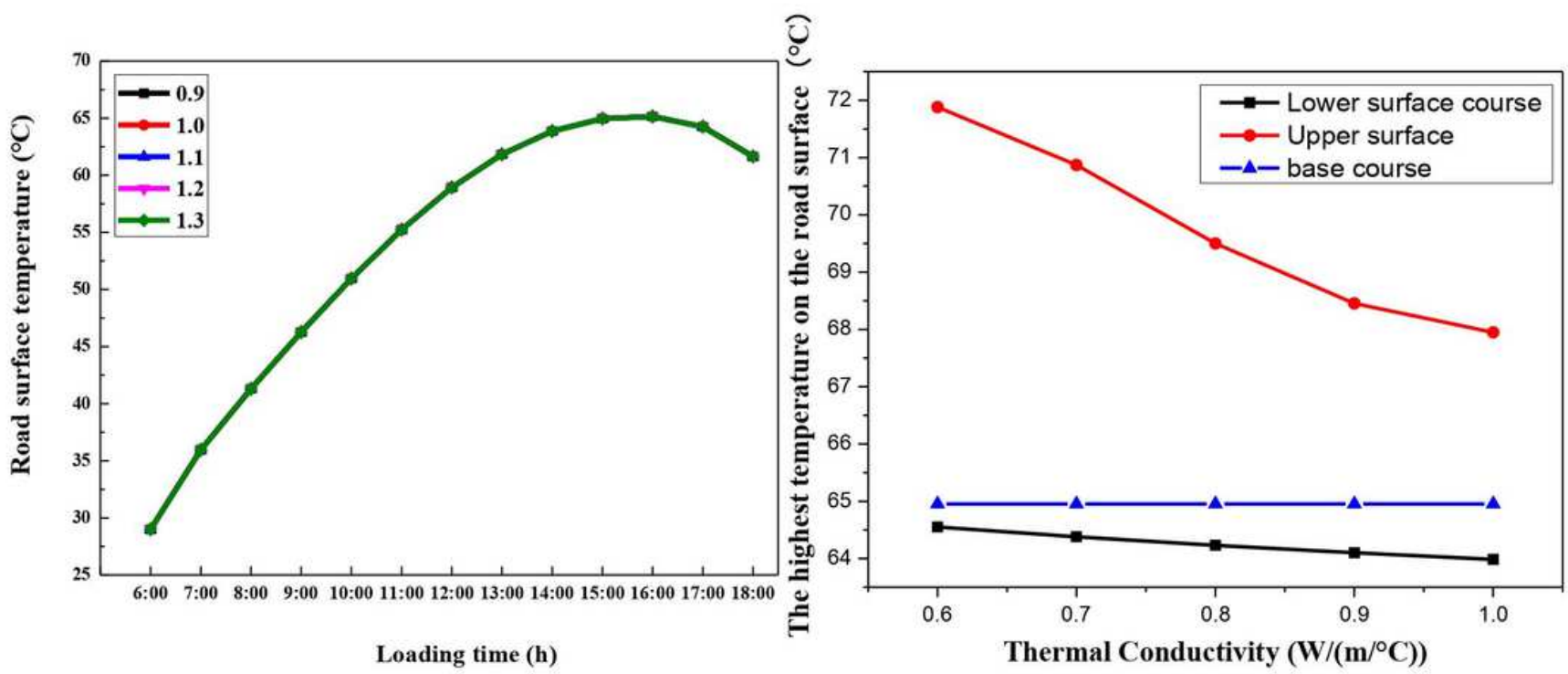

$\begin{array}{ll}\text { (c) Base course } & \text { (d) Maximum surface temperature of the road on a day }\end{array}$

Figure 7

Effect of thermal conductivity on the temperature of permeable pavement surface 


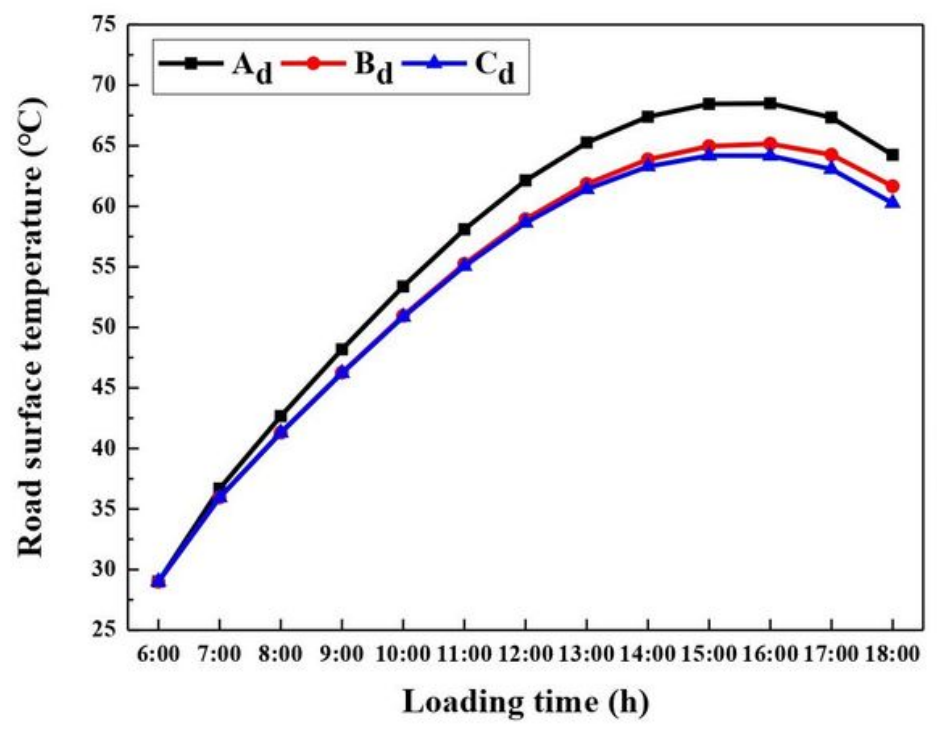

(a) Dry condition

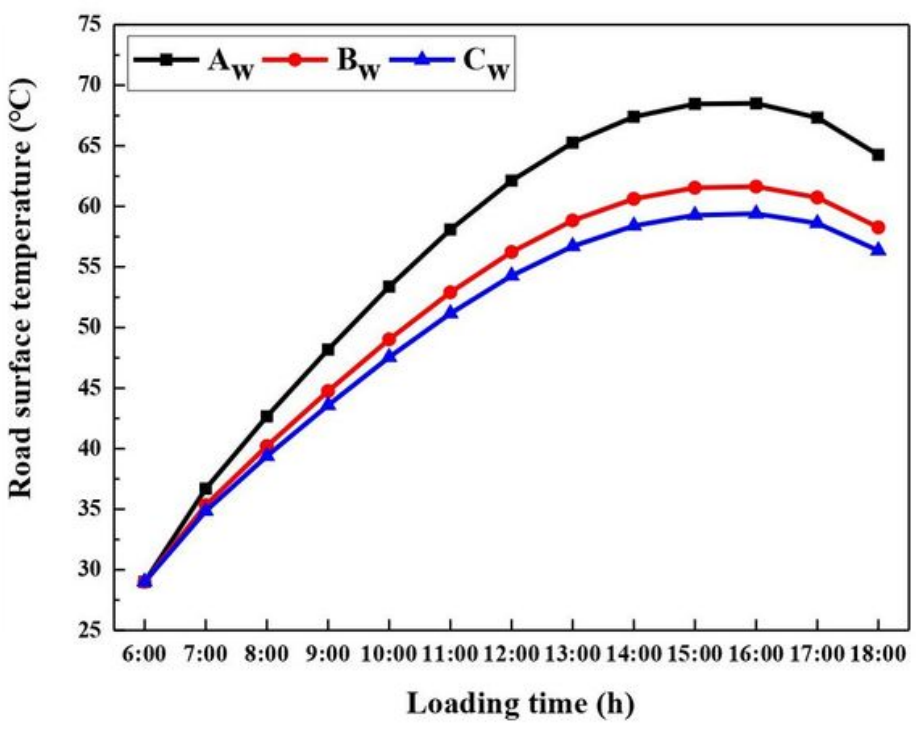

(b) Water-holding condition

\section{Figure 8}

Comparison of road surface temperatures in dry and water-holding conditions 


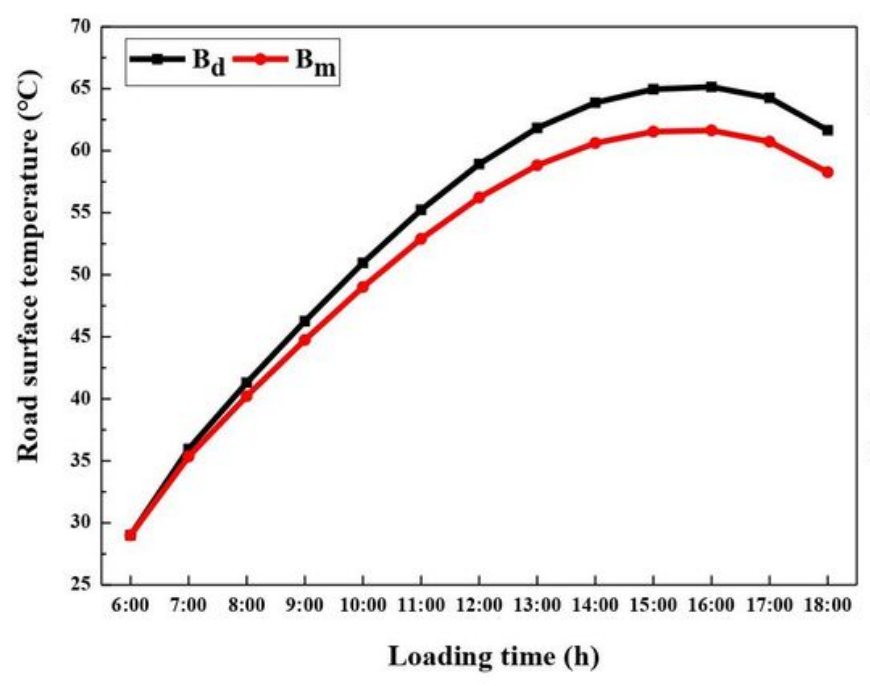

(a) Surface-permeable type structure

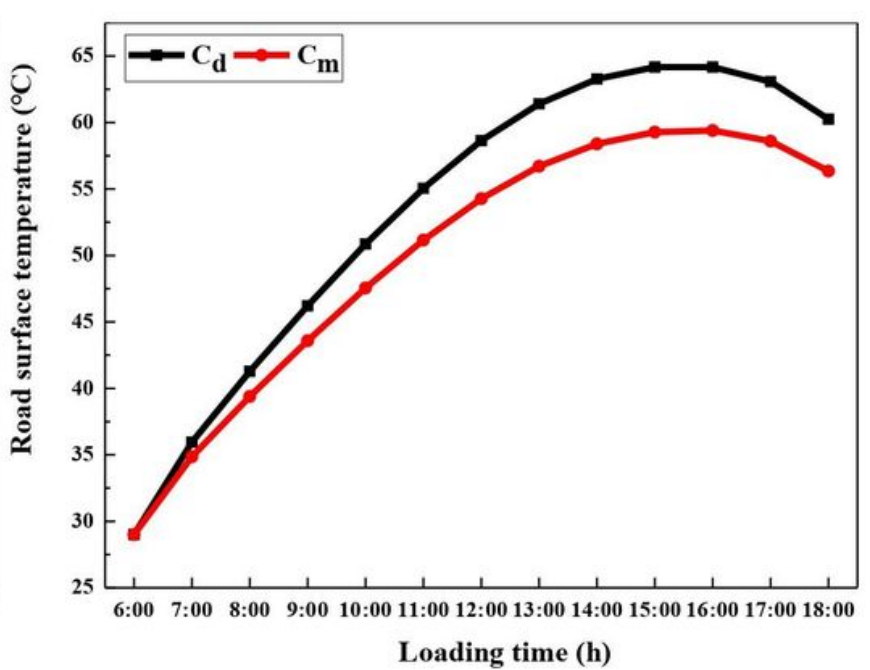

(b) Fully permeable structure

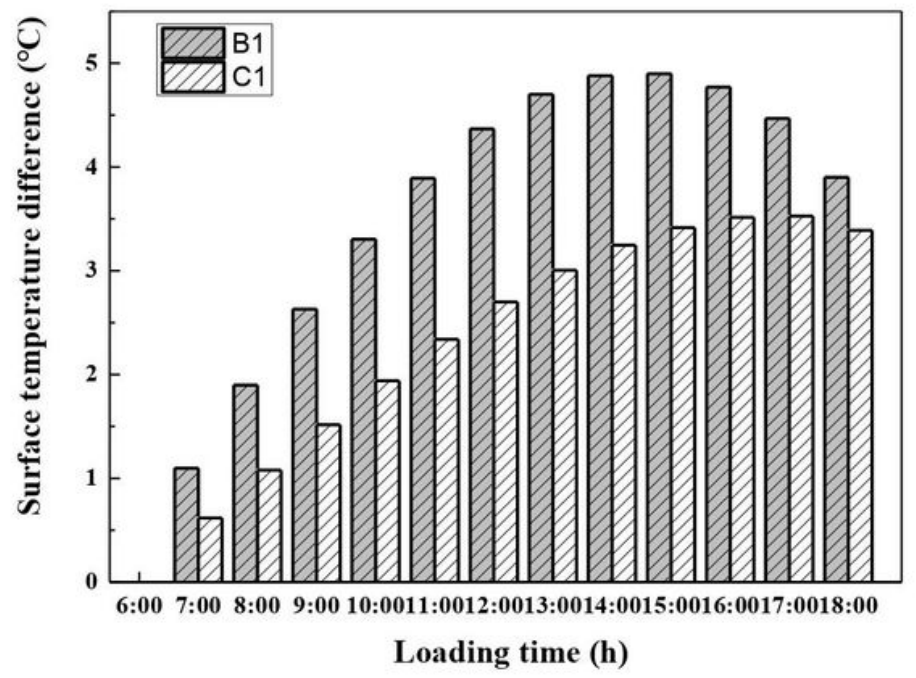

(c) Comparison of temperature difference between wet and dry road surfaces by pavement type

\section{Figure 9}

Comparison of road surface temperature of permeable pavement in dry and water-holding condition 